Alma Mater Studiorum - Università di Bologna DEPARTMENT OF ECONOMICS

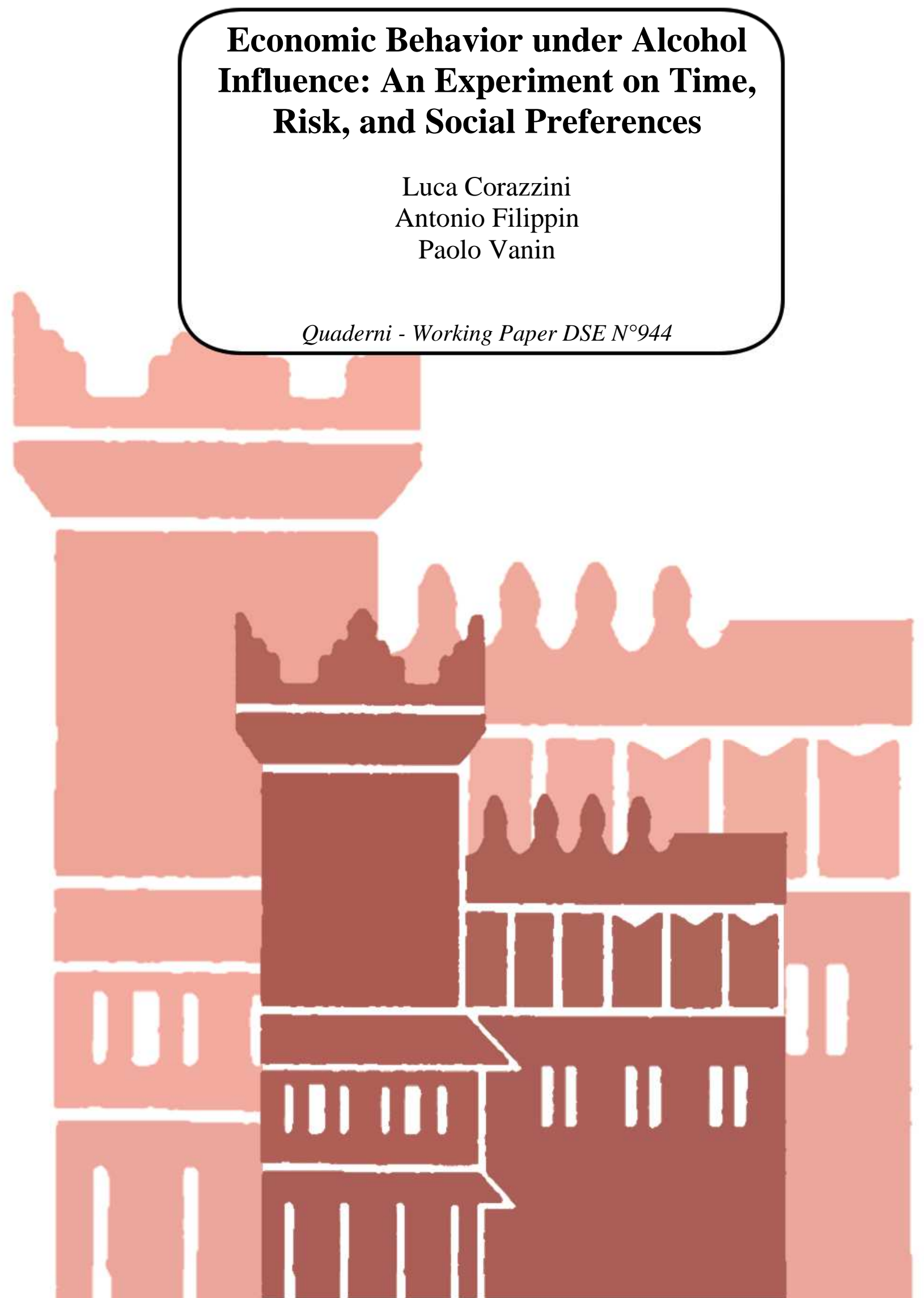




\title{
Economic Behavior under Alcohol Influence: An Experiment on Time, Risk, and Social Preferences th
}

\author{
Luca Corazzini $^{\mathrm{a}}$, Antonio Filippin ${ }^{\mathrm{b}, \mathrm{c}}$, Paolo Vanin ${ }^{\mathrm{d}}$ \\ "University of Padua, Department of Economics and Management "M. Fanno", via del Santo, 33, 35123, Padova, Italy \\ bUniversity of Milan, Department of Economics, Via Conservatorio 7, 20122 Milano, Italy \\ ${ }^{c}$ Institute for the Study of Labor (IZA), Schaumburg-Lippe-Str. 5-9, 53113 Bonn, Germany \\ dUniversity of Bologna, Department of Economics, Piazza Scaravilli 2, 40126 Bologna, Italy
}

\begin{abstract}
We report results from an incentivized laboratory experiment to provide controlled evidence on the causal effects of alcohol consumption on risk preferences, time perception and altruism. Our design allows disentangling the pharmacological effects of alcohol intoxication from those mediated by expectations, as we compare behaviors of three groups of subjects: those participating to an experiment with no reference to alcohol, those exposed to the possibility of consuming alcohol but assigned to a placebo and those having effectively consumed alcohol. Once randomly assigned to one treatment, subjects were administered a series of consecutive economic tasks, being the sequence kept constant across treatments. After controlling for both the willingness to pay and the potential misperception of probabilities as elicited in the experiment, we do not detect any effect of alcohol in depleting subjects' risk tolerance. On the contrary, we find that alcohol intoxication increases impatience. Moreover, we find that alcohol makes subjects less generous as we detect a negative relationship between the blood alcohol concentration and the amount of money donated to NGOs.
\end{abstract}

\section{JEL Classifications: D03; I10; C91}

Keywords: Alcohol, Risk Preferences, Impatience, Laboratory Experiment

\footnotetext{
We would like to thank Giuseppe Vacirca for assistance during the experiment and Giacomo Calzolari, Matteo Galizzi, Silvia Tiezzi and participants to the American Association of Wine Economists 2009 Conference (Reims), the LabSi 2010 Conference (Siena), the Economics of Risky Behaviors 2010 Conference (Atlanta), and the Social Norms and Intertemporal Choice (SoNIC) 2011 seminar (Bologna) for useful suggestions. Vanin gratefully acknowledges support from the Italian Ministry of Research and Education (FIRB 2008, SoNIC, RBFR084L83). The experimental protocol was approved by the ethical committee of the University of Milan. All remaining errors are ours.

Contact: luca.corazzini@unipd.it (Luca Corazzini), antonio.filippin@unimi.it (Antonio Filippin), paolo.vanin@unibo.it (Paolo Vanin)
} 


\section{Introduction}

There is a widespread consensus and social alarm about the potential costs of alcohol consumption, and especially of alcohol abuse. The reason is that alcohol is perceived to enhance risky behaviors and impulsive decision-making, thereby increasing the likelihood of facing unpleasant consequences for oneself as well as for other people. Traffic fatalities, disorders in gambling decisions, detrimental health conditions and risky sexual behaviors represent only a few examples of the potential risks and social concerns associated with alcohol abuse. For instance, according to the World Health Organization, "Alcohol is the world's third largest risk factor for disease burden; it is the leading risk factor in the Western Pacific and the Americas and the second largest in Europe" (Fact sheet, 2011).

The literature in both social sciences and medicine discussed in Section 2 is rich of empirical studies investigating the (harmful) behavioral consequences of substance abuse. In particular, the effects of alcohol consumption on risk, time and social preferences have commanded considerable attention. Given its social relevance, it is important, both for positive reasons and to inform policymaking, to have a precise assessment of the causal behavioral effects of alcohol intoxication. However, their proper identification poses serious methodological difficulties, which, in our view, are not entirely dealt with in many studies.

First, empirical studies of alcohol intoxication based on field data, whether collected from directly observed or from self-reported behavior, typically suffer from self-selection into drinking. They can therefore highlight interesting correlations, but they are usually unable to identify causal effects. ${ }^{1}$ Any correlation between blood alcohol concentration and certain behavioral traits may reflect a true causal effect, but could also stem from different propensity to drink alcohol by individuals with those traits.

Second, and relatedly, individuals usually choose at the same time whether, when, where, with whom and how much to drink alcoholic beverages. This means that it is usually hard to disentangle the effects of alcohol from those of the context in which drinking takes place.

Third, the behavioral effects of alcohol intoxication are partly pharmacological and partly triggered by a psychological reaction to the subjective perception of being under the influence of alcohol. Disentangling the two effects requires independent variations of actual and perceived blood alcohol concentration (with implied relevant misperceptions).

Fourth, as far as the specific effects of alcohol on impulsive decision-making are concerned, a further complication derives from the fact that risk and time preferences are intertwined by construction because the future inherently encapsulates an element of uncertainty. Hence, the effects of alcohol on these preference traits should be jointly studied.

The present paper aims at providing clear causal evidence on the effects of alcohol on risk, time and social preferences, by appropriately tackling the above-mentioned difficulties.

We report results from a laboratory experiment in which subjects participate to a battery of incentivized economic decision tasks in the following interdependent domains: risk attitude, time preferences, optimism, value of money (willingness to pay for an object) and altruism (donations to social projects). This allows identifying the causal effects of alcohol intoxication after adequately controlling for potential confounding factors related to the interdependence between the analyzed economic domains.

\footnotetext{
${ }^{1}$ The same is true for studies of drinking and binge drinking habits.
} 
A distinctive feature of our experiment is that it isolates the pharmacological effects of alcohol due to measured blood alcohol concentration, from the psychological effects due to subjectively perceived intoxication. The pharmacological effect is identified by comparing subjects who are treated with alcohol to those who receive a placebo beverage with no alcoholic content, but whose perceptions are appropriately confounded, so that we can exploit their misperceived blood alcohol concentration. Additionally, by comparing subjects in this placebo treatment to those in an experiment with the same tasks but no reference to alcohol, we are able to isolate the effects of perceived intoxication from the contextual effects induced by the alcoholic framing.

Our results can be summarized as follows. Concerning risk preferences, after controlling for optimism, the willingness to pay and other subjective controls, we only detect a marginal positive effect of alcohol intoxication on risk aversion for female subjects.

On the contrary, we find a strong pharmacological effect of alcohol consumption on time preferences: it makes subjects more impatient. The pure impact of alcohol consumption on time preferences remain substantially large even after taking into account its interplay with subjects' risk attitude. In this respect, net of the pharmacological effect of alcohol intoxication and in line with previous studies, we detect a negative and significant relationship between impatience and risk aversion.

Finally, concerning altruism, our results suggest that alcohol makes subjects more selfish, as we observe a negative and significant relationship between alcohol intoxication and donations to NGOs.

Our results can be interpreted as contributing to the broad debate in behavioral economics, psychology and neuro-sciences on the relative weight of deliberation and emotions for individual decision-making, which is often described as an interaction in the brain between an affective and a deliberative system, with the latter controlling the impulses of the former through the exertion of willpower. If alcohol intoxication raises the cost of exerting willpower, and makes decisions more dependent on the affective system, our results support the view that the 'emotional self' is impulsive and may induce individuals to make decisions that are excessively driven by impatience, which they may subsequently regret.

The rest of the paper develops as follows. The next section discusses the related literature highlighting the contributions of our study. Section 3 describes the design and the proce-

dures of our experiment. Section 4 presents the results along the several lines of inquiry, and Section 5 concludes.

\section{Related literature}

Social scientists have devoted substantial effort to analyze the relationship between alcohol consumption and risky behaviors, with their field of investigation ranging from driving under the influence and corresponding traffic fatalities (Dee, 1999; Levitt and Porter, 2001) to truancy and high-school drop-out (Chatterji and DeSimone, 2005; Duarte and Escario, 2006; Koch and McGeary, 2005), from lower labor productivity and worse labor market outcomes of young adults (Chatterji and DeSimone, 2006) to health diseases (Dills and Miron, 2003), from risky sexual behavior (Grossman et al., 2005; Grossman and Markowitz, 2005) to violent crimes (Markowitz, 2005). Most of these studies are based on survey data and provide useful indications about the potential social costs associated with alcohol abuse. Yet, 
as anticipated in the introduction, self-selection suggests to be cautious in giving a causal interpretation to estimated correlations.

A growing body of studies, based on the idea that (potentially) harmful behaviors are driven, among other things, by risk preferences, have investigated at the individual level the link between alcohol drinking and risk attitude. Barsky et al. (1997), Anderson and Mellor (2008) and Galizzi and Miraldo (2012), among others, show evidence of a significant correlation between risk aversion and alcohol consumption habits, but they also explicitly worn against causal interpretations of their findings.

A few studies look at the individual-level correlation between alcohol intoxication and risk preferences using field experiments, with mixed results. Burghart et al. (2013) find that alcohol makes women more risk prone and has no effect on risk propensity of male subjects. By contrast, Proestakis et al. (2013) find that females' risk aversion increases with both measured and perceived alcohol concentration, while only the latter displays a positive correlation for males. While field experiments improve the external validity of the results, they do not solve the problem of self-selection into drinking. Moreover, they make it difficult to disentangle the pharmacological impact of alcohol intoxication from context and peer effects (Dills and Miron, 2003; Kremer and Levy, 2008). ${ }^{2}$

Laboratory experiments offer better chances of circumventing self-selection problems and identifying the causal effects of alcohol intoxication. Unfortunately, so far they have not provided conclusive results either. Some of them (Breslin et al., 1999; Cutter et al., 1973; Meier et al., 1996; Sjöberg, 1969) report no or mixed effects of alcohol on individual risk attitude. Other ones, such as Lane et al. (2004), identify a positive pharmacological effect of acute alcohol intoxication on risk taking. One advantage of laboratory experiments is also that they allow to compare the effects of acute alcohol subministration with those of placebo treatments, thus in principle allowing to separate the pure pharmacological effects of alcohol from the effects mediated by subjects' expectations (see, e.g., Malani and Houser, 2008). Moreover, they can also be used to disentangle the effects of alcohol from those of the drinking context. ${ }^{3}$

There is also a growing literature suggesting that alcohol (and other substance) abuse tend to induce impulsive decision-making. ${ }^{4}$ A considerable number of studies have investigated whether substance abusers, and smokers in particular, are more impulsive, finding largely supportive evidence (Ainslie and Haendel, 1983; Bickel et al., 2001). Yet, once again, correlation does not mean causality. On the one hand, it could be that subjects become abuser because they are impatient, as suggested for instance by Poulos et al. (1995). Moore and Cusens (2010) support the same interpretation and consider the acute alcohol consump-

\footnotetext{
${ }^{2}$ Peer effects have received increasing attention in recent years in the literature on alcohol abuse and risky behaviors, with studies focusing on the role played by fraternity membership (DeSimone, 2007, 2009), social as well as family influence (Buonanno and Vanin, 2013) and exposure to "wrong" friendships (Lundborg, 2006).

${ }^{3}$ By making social interactions salient in their experimental design, Abrams et al. (2006) report that the positive effects of alcohol consumption on risk taking behaviors are stronger when subjects act individually rather than when they participate in group decision-making.

${ }^{4}$ Impulsivity is commonly defined in the psychological literature as the tendency to choose smaller and sooner rewards over larger and later ones although the latter are preferred when the decision is not made under the heat of the moment. This form of preference reversal is usually explained in terms of hyperbolic discounting, and has stimulated a large body of empirical research.
} 
tion of subjects recruited in a pub. On the other hand, it is also possible that substance abuse makes subjects more impatient. Petry (2001) claims that alcohol addicted subjects are characterized by a steeper discounting of delayed rewards and Field et al. (2007) find similar evidence among adolescents. Vuchinich and Simpson (1998) document that heavily drinking college students discount hypothetical delayed rewards more steeply than light drinkers. ${ }^{5}$ Again, given these considerations, controlled experiments are necessary to identify the direction of the causal link between time discounting and alcohol consumption.

Unfortunately, even in this case, randomized experiments yield no clear-cut results. Ortner et al. (2003) find that increased alcohol consumption leads to a counterintuitive increase in patience, whereas Richards et al. (1999) find no significant effect. Both experiments entail a within subject design in which the task amounts to choose more than one hundred times between different combinations of current and delayed rewards. This implies that each decision has been made under very weak incentives given the pay-one-at-random mechanism involved. Reynolds et al. (2006) use a different procedure to elicit time preferences, namely the Experiential Discounting Task (EDT). With this real time method choices are delayed within the experiment by a few seconds. Furthermore, choices are confounded by a probabilistic component because later rewards were also uncertain. The authors find a significant difference between subjects intoxicated at $8 \mathrm{~g} / \mathrm{kg}$ and the placebo treatment, but not when comparing the results of the $.4 \mathrm{~g} / \mathrm{kg}$ condition with the other two.

A further relevant methodological complication concerns the interplay between risk and time preferences mentioned in the introduction. The psychology literature considers delay and risk discounting as similar if not identical processes, and they are often not disentangled. However, the two concepts are clearly distinct from both a theoretical and an empirical point of view. For instance, Andreoni and Sprenger (2012) emphasize how a certainty effect at the risk level prevails over delay discounting: subjects disproportionately prefer certain outcomes over probabilistic alternatives regardless of being sooner or later in time. Green and Myerson (2004) argue that the same form of hyperbola-like function describes discounting of both delayed and probabilistic outcomes, but there is a large variety of recent findings that are inconsistent with a single-process account. Holt et al. (2003) find that gamblers show a higher risk tolerance than non-gamblers, while they do not discount delayed rewards more than the control group. Interestingly, Drichoutis and Nayga (2010) test whether induced mood states have an effect on elicited risk and time preferences. Risk preferences between subjects in the positive and negative mood treatments do not significantly differ. By contrast, subjects induced into a positive mood exhibit higher discount rates.

The fact that the future is uncertain seems to suggest that the more one dislikes uncertainty, the more one wants to be compensated not only for facing risks but also for postponing a gratification. Thus, a positive correlation between risk aversion and impatience should be observed. On the other hand, impulsivity can be seen as a general trait that includes both an inability to delay gratification (impatience) and a tendency to take risk. In this case a negative, rather than positive, correlation between impatience and risk aversion should be expected. ${ }^{6}$ Evidence in the literature is again mixed. For instance Menon and Per-

\footnotetext{
${ }^{5}$ Kirby and Petry (2004) find higher discount rates, when compared to controls, among heroin and cocaine users but not among alcoholics.

${ }^{6}$ This is the typical interpretation of impulsivity in the psychology literature.
} 
ali (2009) report that risk aversion increases with impatience, while Anderhub et al. (2001) find opposite results, i.e. a significantly negative correlation between subjects' degrees of risk aversion and their (implicit) discount factors. Our contribution to this ongoing debate is twofold. First, for each subject, we elicit both risk and time preferences. In this respect, our evidence supports the existence of negative relationship between impatience and risk aversion. Second, our design allows studing how these behavioral domains is affected by alcohol intoxication.

Overall, the previous considerations suggest that identifying the causal effects of alcohol consumption on both risk attitude and time preferences still represents an open question for social scientists. Our study contributes to this flourishing literature by providing novel evidence obtained by means of an experimental design that minimizes the impact of the abovementioned identification issues.

\section{The Experimental Design}

Our experimental study investigates the causal effects of alcohol consumption on individual decision-making. We compare results from two experiments: NO-ALC and ALC. In our benchmark, the NO-ALC experiment, subjects took incentivized economic decisions without consuming (and being exposed to any reference to) alcohol. The ALC experiment involved the same tasks as the benchmark, but before performing such tasks subjects were required to drink a beverage, which they knew could contain alcohol. In fact, some of them (chosen at random) received a truly alcoholic beverage, whereas the other ones received a non-alcoholic drink with only the smell of alcohol. Thus, we can distinguish between three treatments: the benchmark NO-ALC, with no reference whatsoever to alcohol; the alcohol treatment ALC-T, whose subjects made economic decisions having effectively consumed alcohol; and the placebo group ALC-P, whose subjects were not treated with alcohol but may have believed they were treated. We measured both actual and perceived blood alcohol concentration (BAC) at different stages of the experiment.

By comparing the economic decisions of subjects in NO-ALC and in ALC-P, we identify the pure placebo effect of alcohol, due to the belief of having drunk (see e.g. Malani and Houser, 2008). On the other hand, by comparing the economic decisions in the two treatments with alcohol reference, ALC-P and ALC-T, we identify the pure pharmacological effect of alcohol consumption (i.e., controlling for the belief of having drunk and thus net of expectation-mediated effects).

\subsection{Procedures}

The experiment involved voluntary students recruited with mailing list systems. The email used to recruit subjects in ALC announced that the experiment might involve the consumption of a moderate quantity of alcohol. In this case, we explicitly required that volunteers already consumed alcohol before in their life without experiencing any problem, and that their physical and mental conditions did not advise against the consumption of a moderate amount of alcohol. On their arrival at the laboratory, participants in ALC were reminded that the experiment might involve alcohol consumption and that they could withdraw from the study at any time. After having signed a consent form, subjects randomly drew a number representing their ID during the experiment. On the one hand, the number was used to link subjects to final earnings in an anonymous way. Once seated, 
subjects were required to type in their number on the computer and, at the end of the experiment, they were paid by using envelopes that reported ID numbers. On the other hand, the number was also used to randomly assign subjects to the two treatments, ALC-P and ALC-T. Subjects were never told to which treatment they were assigned. Indeed, no reference was made to the existence of two treatments: it was only publicly announced that the experiment involved the possibility of alcohol consumption. A medical doctor ascertained through anamnesis and visit that each participant was suitable for the experiment without health risks associated with the (potential) consumption of a moderate quantity of alcohol.

Before consuming the beverage, all participants were given an extra strong lozenge ("Fisherman's Friend") to disguise the taste and making detection of the actual alcohol content more difficult. Subjects in ALC-T drunk a mixture of peach juice and ethanol. The amount of ethanol was targeted according to the tables released by the Italian Health Ministry with the purpose of reaching an average intoxication level about $0.8 g / l$, which constitutes the limit to drive under the influence in several countries. ${ }^{7}$ Those in ALC-P instead drunk peach juice with $5 \mathrm{ml}$ of grappa passed on the border of the glass and floated on the surface: a quantity that can barely be registered by means of a breath alcohol test, but that gave the glass the characteristic smell of alcoholic beverages.

All participants were given 6 minutes to consume the beverage, being instructed that they should stop drinking right away had they experienced any unpleasant effect. In the 30 minutes after drinking (before alcohol consumption could alter the comprehension of the tasks), subjects were briefed by reading instructions explaining the mechanism proposed by Becker et al. (1964) (henceforth, BDM) aloud. BDM is an incentive compatible device that was used in three out of five tasks of our experiment to elicit reservation prices. Under BDM, an individual reports a bid (ask) for an item. Then, the price of the item is randomly drawn. If the bid (ask) is above (below) the price, the subject receives (sells) the good and pays (receives) the drawn price. If the bid (ask) is below (above) the price, the subject does not receive (sell) the good and pays (receives) nothing. ${ }^{8}$ An important feature of BDM that makes this device useful for our purposes is that it can be easily adapted to different economic tasks.

Immediately before starting with task performance, participants had their Blood Alcohol Concentration (BAC) measured with a Lion500 professional alcoholmeter without being told the result. In addition, subjects were also asked to self-report what they believed their intoxication level to be by using the same scale of the alcoholmeter. Overall, this process lasted about 15 minutes. Measured and perceived BAC, respectively recorded in the $M B A C$ and $P B A C$ variable, allow us to identify both the pharmacological and the indirect, expectation-mediated effects of alcohol consumption on subjects' economic decisions.

The NO-ALC experiment was identical to the ALC one, but for the removal of any alcohol-related element. Subjects in NO-ALC did not consume any alcohol, and indeed alcohol was never mentioned either in the recruiting email or during the experiment. To remove any reference to possible intoxication, subjects in NO-ALC did not meet the doctor

\footnotetext{
${ }^{7}$ Subjects in ALC-T received on average $0.8 \mathrm{ml}$ of ethanol per $\mathrm{kg}$ of body weight (measured at the beginning of the experiment), with the exact quantity varying between $0.67 \mathrm{ml} / \mathrm{kg}$ and $1 \mathrm{ml} / \mathrm{kg}$ depending on gender, recent food intake, and drinking habits.

${ }^{8} \mathrm{~A}$ detailed explanation of the BDM mechanism as provided to the subjects is attached in the Appendix together with the instructions for the experimental tasks explained below.
} 
for the anamnesis and the visit, nor had their measured and perceived BAC recorded. Nevertheless, in order to minimize the difference in time duration between the two experiments, we implemented the same BDM briefing stage in NO-ALC as in ALC. Apart from alcohol involvement, the two experimental designs coincided in all other respects.

\subsection{The Tasks}

In both ALC and NO-ALC, after the introductory phase, subjects were required to take consecutive, non-strategic economic decisions in the following domains: risk attitude, willingness to pay, altruism, optimism and impatience. Given the large number of tasks implemented, we deliberately decided to keep the same order of economic decisions between experiments. Thus, differences in behaviors between ALC and NO-ALC can only be imputed to the different alcoholic treatment. The tasks were computerized using $\mathrm{z}$-Tree (Fischbacher, 2007), a flexible computer platform that is widely used in experimental economics to administer incentivized experiments in networks. The choice of the tasks was intended to cover a large spectrum of aspects, amply studied by the economic literature on individual decisionmaking. The tasks were implemented in an incentive compatible way. Subjects were told that although they were going to make several economic decisions, their final payments would depend on a single task randomly selected at the end of the experiment. It is worth noticing that, in calibrating parameters involved in the tasks, we tried to make potential earnings substantially comparable across treatments.

Risk attitude (Phase 1). We measured the risk attitude of subjects by eliciting their ask prices in a battery of 10 lotteries using the Becker et al. (1964) mechanism. Lotteries entail the same events ( 0 euro vs. 40 euro gains) with different winning probability, ranging from $10 \%$ to $100 \%$. Lotteries were presented in the same randomly prearranged order to reduce anchoring effects that might induce risk neutrality. This elicitation method is not the most widely used, and it has been criticized because of the high cognitive load required (Harrison and Rutström, 2008). Complexity is definitely one of the most relevant dimensions along which the elicitation tasks should be evaluated (Crosetto and Filippin, 2013). However, the design of our experiment has subjects exposed repeatedly to the BDM mechanism. Therefore, the adoption of BDM to measure risk attitude implies no additional cognitive load at the margin, something that would have happened instead had we chosen another risk elicitation method requiring additional instructions, such as the Holt and Laury (2002). Moreover, as already mentioned, subjects were appropriately briefed on the working of BDM in the introductory phase. This task also has the advantage of allowing to measure subjects' risk attitude along the whole domain of probabilities. As a summary measure of risk attitudes we use the average difference between the expected value and the ask price (or selling price) across all the lotteries. According to standard rational choice models of individual decisionmaking, this variable, henceforth called Risk aversion, should be equal to zero, positive and negative for risk neutral, risk averse and risk loving individuals, respectively. One of our main research questions concerns the effect of actual or perceived BAC on Risk aversion.

Willingness to pay (Phase 2). In this phase subjects were endowed with 20 euro and we measured their willingness to pay for a radio-videogame by using the above mentioned BDM and recording their bid price. For given tastes, this variable, henceforth referred to as WTP, 
reflects the value (or marginal utility) subjectively attributed to money, and should be distributed in the same way across random samples of the population. The design of monetary incentives in experiments is usually based on the assumption of constant marginal utility of money, which is crucial to keep incentives constant and therefore identify the causal effects of a treatment. In the context of our experiment, this assumption cannot be taken for granted. Actual or perceived alcohol exposure could alter subjects' willingness to spend money, possibly threatening the correct identification of the causal effects of alcohol on our main variables of interest, risk and time preferences. The same monetary incentives could be perceived differently by intoxicated subjects. Another possibility is that alcohol exposure impairs subjects' ability to make rational choices, making results for subjects in ALC more noisy. These two effects can be directly investigated using the mean and the variance of WTP across treatments, and the can be controlled for including these variables in multivariate regressions.

Altruism (Phases 3 and 4). In each of these two phases subjects were endowed with 20 euro and were involved in a dictator game, in which they had to choose how much to donate (if anything) to a given non-governmental organization (NGO). The two phases differed in the selected NGO: the humanitarian aid agency Médecins Sans Frontières in one case and the Italian website of economic information LaVoce.info in the other. We measured altruism by the amount donated to these two NGOs, respectively recorded in the Altruism MSF and Altruims $L V$ variables. We investigate whether and how alcohol affects altruism, and in particular whether it has a different impact on the propensity to make donations to a "hot" cause (Médecins Sans Frontières) and to a "cold" one (LaVoce.info). This analysis complements the study of the effects of alcohol on risk and time preferences and extends it to social preferences.

Optimism (Phase 5). We assessed subjects' optimism by randomly extracting a sample of 21 covered cards out of a maze of 52 poker cards. Each participant drew one card from the extracted sample and won 1 euro for each card in the sample that had the same color as his or hers. Subjects were then asked to report how many of the 21 cards they expected to be of the same color as their own. Such beliefs, captured by a variable called Optimism, were elicited in an incentive compatible way by assigning a prize of 10 euro if they turned out to be correct. Due to the random extraction, the expected value is that the extracted sample contains 10.5 cards of any color. Higher levels of Optimism thus reflect an optimistic view of one's chances of earning money. Besides its intrinsic interest, this task offers an important control for the study of the effects of alcohol on risk attitude. If actual or perceived alcohol exposure altered the perception of probabilities, they could modify subjects' propensity to make risky choices not because of a change in risk preferences, but because of a change in optimism about the likely consequences. The variable Optimism allows controlling for this possibility.

Impatience (Phase 6). In this phase each subject was given a cash card in which the experimenters would transfer 20 euro one hour after the end of the experiment. We measured participants' impatience by asking them how much money they would require in order to postpone the money transfer by one, seven, and eight days. Such requests, recorded as One day, Seven days and Eight days, respectively, were made incentive compatible through 
the already discussed BDM mechanism. The use of a cash card allowed measuring subjects' time preferences by cleanly controlling for trust and transfer costs. It is worth noticing that we deliberately chose to implement the impatience task at the end of the experiment. Indeed, we tried to enhance the salience of postponing monetary amounts by minimizing the time distance between the task and the final payments.

\subsection{Debriefing}

The data collection phase lasted 30 minutes and finished with subjects filling in an anonymous questionnaire aimed at gathering demographic and socio-economic information as well as some self-reported measures of happiness and trust. Following data collection, participants in ALC had their measured and perceived BAC recorded for the second time, with subjects obviously unaware of the result of the first measure. The respective variables are called $M B A C 2$ and $P B A C 2$. Participants in ALC who displayed a measured BAC above $0.5 \mathrm{~g} / l$ were invited to remain in the laboratory until their BAC decreased below such a threshold (the legal limit allowed to drive in Italy) and we suspended the payment until that moment. Before leaving the laboratory, all subjects were asked to sign a statement in which they declared that they felt physically and mentally comfortable and that no impairment was perceived following the participation to the experiment. Figure 1 summarizes the timing of the experiment.

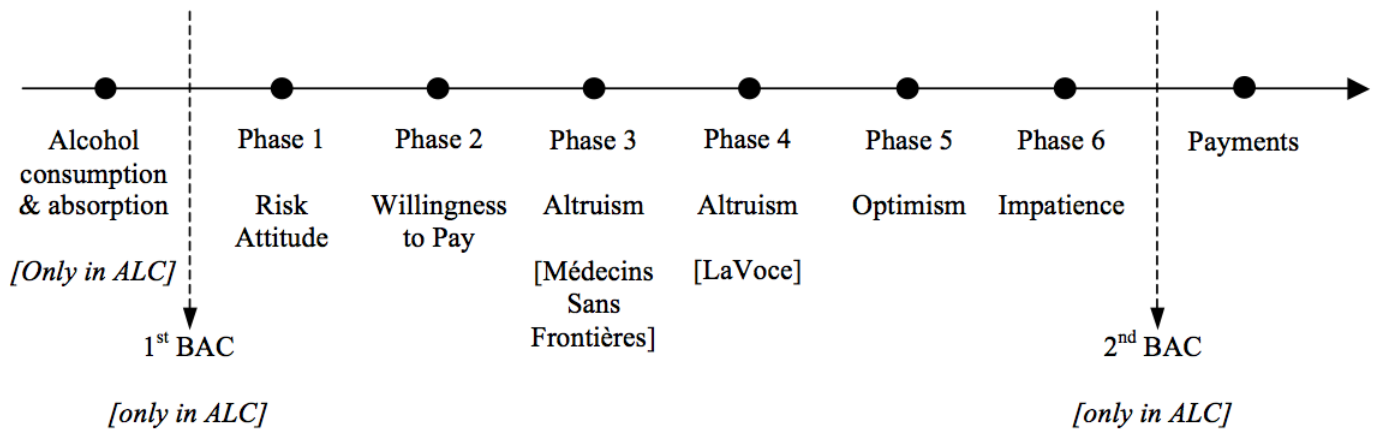

Figure 1: Timeline of the Experiment

\section{Results}

In the statistical analysis, we use data from 3 sessions of ALC and 3 sessions of NO-ALC. Overall, we involved 39 subjects in ALC and 38 subjects in NO-ALC, who were mainly undergraduate students of Economics. On average, subjects earned 13.85 euros, for sessions lasting about 90 minutes in ALC and 70 minutes in NO-ALC. The experiment took place at the University of Milan between March and December 2011. Table 1 presents the summary statistics for age, gender and performance in the various tasks, separately for ALC and NOALC.

\subsection{Measured and perceived BAC}

Before looking at the effects of alcohol, it is worth considering the differences in measured and perceived BAC induced by the random allocation of subjects in ALC to the alcohol (ALC-T) and placebo (ALC-P) treatment. These are shown in Table 2, which presents 
Table 1: Summary statistics

\begin{tabular}{l|cccc|cccc}
\hline \hline \multicolumn{1}{c|}{ Treatment } & \multicolumn{4}{c|}{ ALC (39 Obs) } & \multicolumn{3}{c}{ NO-ALC (38 Obs) } \\
\hline \multicolumn{1}{c}{ Variable } & Mean & Std. Dev. & Min & Max & Mean & Std. Dev. & Min & Max \\
\hline Age & 23.128 & 1.922 & 20 & 30 & 24.605 & 5.38 & 19 & 45 \\
Female & .333 & .478 & 0 & 1 & .579 & .5 & 0 & 1 \\
WTP & 3.521 & 4.159 & 0 & 18.8 & 7.029 & 4.941 & 0 & 20 \\
Optimism & 10.667 & 2.03 & 6 & 13 & 11.711 & 2.779 & 8 & 21 \\
Risk aversion & 1.127 & 5.81 & -9.3 & 19.09 & 1.536 & 5.251 & -4.22 & 17.65 \\
One day & 5.949 & 5.982 & 0 & 20 & 5.403 & 5.592 & 0 & 20 \\
Seven days & 9.524 & 5.52 & 0 & 20 & 8.388 & 5.837 & 0 & 20 \\
Eight days & 11.462 & 6.093 & 0 & 20 & 9.618 & 6.582 & 0 & 20 \\
Donation $M S F$ & 5.882 & 5.68 & 0 & 20 & 9.5 & 5.831 & 0 & 20 \\
Donation LV & 2.603 & 3.285 & 0 & 15 & 4.982 & 4.022 & 0 & 15 \\
\hline \hline
\end{tabular}

by treatment the summary statistics of measured and perceived BAC at the first (MBAC and $P B A C)$ and second $(M B A C 2$ and $P B A C 2)$ recording, respectively. For later use in the analysis, the table also displays summary statistics for misperceived $B A C$, defined as the difference between perceived and measured BAC, at the two recording times (i.e., $M P B A C$ $=P B A C-M B A C$ and $M P B A C 2=P B A C 2-M B A C 2)$. This variable captures the belief of being intoxicated that is not backed by a pharmacological counterpart: for instance, a value of $M P B A C>0$ indicates that the subject overestimates his intoxication level. The misperceived BAC will be used as a proxy of the placebo effect of alcohol. As no specific reference to alcohol is made in the NO-ALC experiment, for its participants we set both BAC and misperceived BAC measures equal to 0 . We will use $M B A C$ and MPBAC (together with a dummy for the NO-ALC experiment) as main explanatory variables.

Table 2: Measured and perceived BAC by treatment

\begin{tabular}{l|cccc|cccc}
\hline \hline Treatment & \multicolumn{4}{|c|}{ ALC-T (20 Obs) } & \multicolumn{4}{c}{ ALC-P (19 Obs) } \\
\hline \multicolumn{1}{c}{ Variable } & Mean & Std. Dev. & Min & Max & Mean & Std. Dev. & Min & Max \\
\hline$M B A C$ & .596 & .159 & .32 & .91 & .017 & .03 & 0 & .08 \\
$M B A C 2$ & .557 & .114 & .32 & .77 & .01 & .024 & 0 & .07 \\
PBAC & .715 & .319 & .2 & 1.5 & .369 & .246 & 0 & .8 \\
PBAC2 & .493 & .218 & .09 & 1 & .241 & .214 & 0 & .65 \\
$M P B A C$ & .119 & .32 & -.38 & .75 & .352 & .234 & 0 & .74 \\
$M P B A C 2$ & -.064 & .235 & -.47 & .63 & .231 & .209 & 0 & .6 \\
\hline \hline
\end{tabular}

At both recording times, perceived and measured BAC are significantly higher in ALC-T than in ALC-P. ${ }^{9}$ At the first recording, before performing the incentivised tasks, experimental subjects in both treatments tend to overestimate their intoxication level: $P B A C$ is on average significantly higher than $M B A C$. Figure 2 shows the distribution of the first recording of measured and perceived BAC for the ALC-T subjects. ${ }^{10}$

At both recording times, the difference between perceived and measured BAC is signif-

\footnotetext{
${ }^{9} \mathrm{~A}$ Mann Whitney test rejects the null hypothesis that measured BAC is on average equal between the two treatments $(p<0.0001$ both for $M B A C$ and for $M B A C 2)$. An analogous test for perceived BAC rejects equality
} 


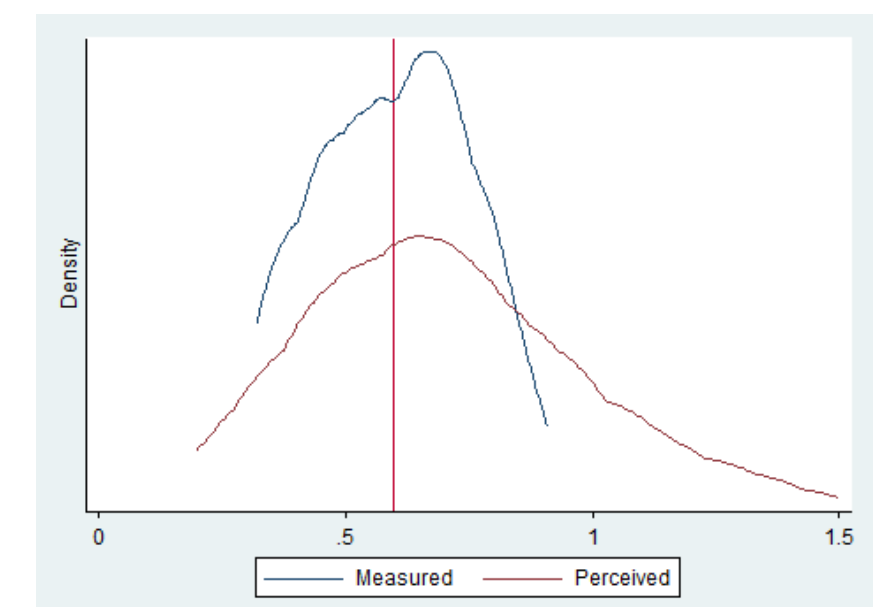

Note: The figure refers to the first recording of BAC for the ALC-T subjects

Figure 2: Measured and Perceived Alcohol Concentration

icantly higher in ALC-P than in ALC-T. ${ }^{11}$ Figure 3 shows the distribution of MPBAC in the two ALC conditions. In general, our design has revealed to be effective at inducing the belief of being exposed to the consumption of alcohol among subjects assigned to the placebo. This offers a good basis to identify the pharmacological and placebo effects of alcohol, since it reduces the positive and strong correlation between perceived and actual alcohol intake that is usually found. In fact, the correlation between perceived and measured BAC is around 0.5 (0.566 for PBAC and MBAC, 0.520 for PBAC2 and MBAC2).

Since perceived $B A C$ at the second recording may be endogenous to performance in the experiment, we will base all the analysis on the first recording. We have also run all the regressions with BAC measures from the second recording, obtaining results that are highly aligned due to the extremely high correlation between the two recording times $(0.978$ for MBAC and MBAC2, 0.918 for PBAC and PBAC2). ${ }^{12}$

\subsection{Alcohol, monetary incentives and optimism}

The sufficiently large monetary incentives involved in the experiment contribute to the methodological validity of our design. Nevertheless, the assumption that subjects with different alcohol exposure perceive monetary incentives in the same way cannot be taken for granted. To correctly identify whether subjects with higher BAC (measured or perceived) value money differently from subjects with lower or no alcohol exposure, we compare their

between the two treatments with p-value 0.0009 for PBAC and 0.0018 for PBAC2.

${ }^{10} \mathrm{At}$ the second recording, after performing the tasks, in both treatments they revise their perceived BAC downwards. In ALC-T, the revision in perception substantially overestimates the objective decrease in measured $\mathrm{BAC}$, with $P B A C 2$ becoming lower than $M B A C 2$ on average. In ALC-P, the perceived BAC remains remarkably high despite the fact that subjects were not exposed to actual alcohol consumption.

${ }^{11} \mathrm{~A}$ Mann Whitney test rejects the null hypothesis that such difference is on average equal between the two treatments with $p=0.0064$ for $M P B A C$ and $p<0.0001$ for $M P B A C 2$.

${ }^{12}$ These results, which are available upon request, are not included because they are less interpretable due to the abovementioned endogeneity issue. 


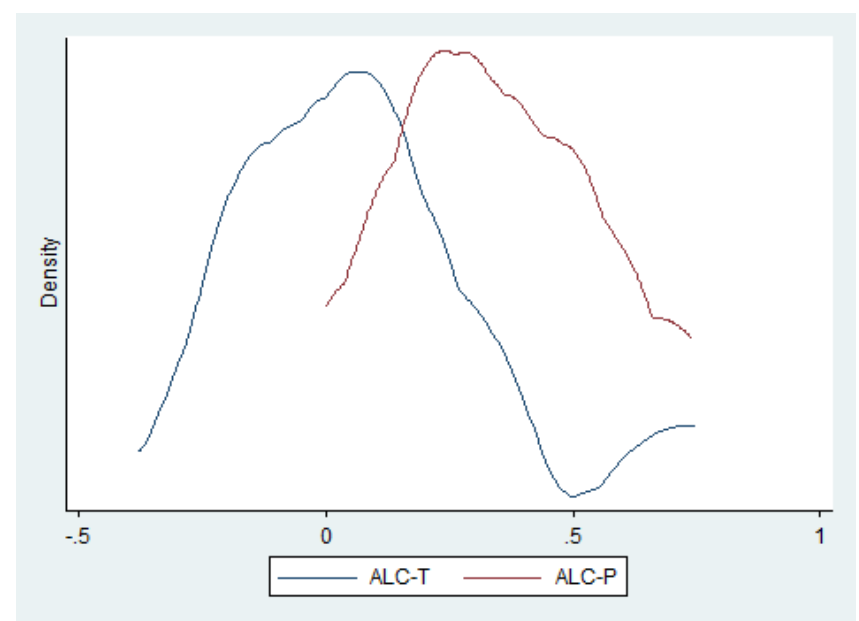

Figure 3: Misperception of Blood Alcohol Concentration (MPBAC)

willingness to pay for a given object (a radio-videogame), as elicited in Phase 2 of the experiment.

Columns 1 and 2 of Table 3 show ordinary least squares (OLS) estimates from a linear model in which the willingness to pay, $W T P$, is regressed against $M B A C, M P B A C$ and NO$A L C$, first without and then with additional exogenous individual controls. It emerges that subjects display a significantly higher willingness to pay when no reference is made to alcohol. A possible interpretation is that in the NO-ALC condition subjects do not have to bear the risk of being exposed to alcohol consumption and implicitly they consider the experiment as less effort demanding than their counterparts in the ALC treatments. Consequently they could dispose more easily of their money because they perceive it relatively more as windfall gains. This interpretation is also consistent with the findings about altruism reported below. ${ }^{13}$ Yet, within an environment with alcohol exposure (ALC), differences in $M B A C$ and in MPBAC do not translate into significant differences in the value of money. ${ }^{14}$ This is reassuring for the validity of the comparison between subjects in treatment ALCT and ALC-P, but in any case we will use the individual WTP as a control in the analysis below.

Notice that the variance of WTP is slightly lower in ALC than in NO-ALC (see Table 1), suggesting that the levels of alcohol intoxication observed in the experiment neither introduce additional noise in subjects' choices, nor impair their ability to make rational choices. Again, this is reassuring for the possibility to interpret subsequent results within the rational choice framework.

The assessment of the effects of alcohol on risk aversion also relies on the assumption that alcohol does not alter the perception of probabilities (in particular, of the odds of winning). We investigate the validity of this assumption by looking at the effects of alcohol intoxication on subjects' optimism as elicited in Phase 5. If alcohol affects optimism, this

\footnotetext{
${ }^{13}$ An alternative explanation is that exposure to alcohol triggers self-control mechanisms on expenditures.

${ }^{14}$ These results are confirmed by non-parametric analysis. A Mann Whitney test rejects the null hypothesis that the average WTP is equal between NO-ALC and ALC (p-values 0.0007) or between NO-ALC and ALC-P ( $p$-value 0.0101), whereas equality between ALC-T and ALC-P cannot be rejected ( $\mathrm{p}$-value 0.4561).
} 
Table 3: Alcohol, value of money and optimism

\begin{tabular}{|c|c|c|c|c|}
\hline \multirow[t]{2}{*}{ Dependent variable } & WTP & WTP & Optimism & Optimism \\
\hline & $(1)$ & $(2)$ & (3) & $(4)$ \\
\hline$\overline{M B A C}$ & $\begin{array}{c}-.3290 \\
(1.0257)\end{array}$ & $\begin{array}{l}-.4036 \\
(.8093)\end{array}$ & $\begin{array}{l}.7282 \\
(.6841)\end{array}$ & $\begin{array}{l}-.6894 \\
(.8120)\end{array}$ \\
\hline$M P B A C$ & $\begin{array}{c}.0307 \\
(1.0340)\end{array}$ & $\begin{array}{l}.6089 \\
(.9757)\end{array}$ & $\begin{array}{c}-1.9665^{* *} \\
(.7989)\end{array}$ & $\begin{array}{c}-1.5074 \\
(.9584)\end{array}$ \\
\hline$N O-A L C$ & $\begin{array}{c}3.4119^{* *} \\
(1.5996)\end{array}$ & $\begin{array}{c}3.1607^{*} \\
(1.6485)\end{array}$ & $\begin{array}{l}.3581 \\
(.5163)\end{array}$ & $\begin{array}{l}.4168 \\
(.6322)\end{array}$ \\
\hline Age & & $\begin{array}{l}.0499 \\
(.0874)\end{array}$ & & $\begin{array}{c}-.0878^{* * *} \\
(.0215)\end{array}$ \\
\hline Female & & $\begin{array}{c}1.1739 * \\
(.6944)\end{array}$ & & $\begin{array}{l}.7731 \\
(.5509)\end{array}$ \\
\hline Constant & $\begin{array}{c}3.6168^{* * * *} \\
(1.2890)\end{array}$ & $\begin{array}{l}1.9608 \\
(2.6524)\end{array}$ & $\begin{array}{c}11.3524^{* * *} \\
(.4891)\end{array}$ & $\begin{array}{c}13.0064^{* * *} \\
\quad(.8498)\end{array}$ \\
\hline Observations & 77 & 77 & 77 & 77 \\
\hline R-Square & .132 & .1477 & .0691 & .1065 \\
\hline
\end{tabular}

Notes: OLS regressions. The dependent variable in columns (1) and (2), WTP, is the willingness to pay for the object in Phase 2 of the experiment; the dependent variable in columns (3) and (4), Optimism, is the expected gain in the card game (elicited in Phase 5). $M B A C$ is the measured level of Blood Alcohol Concentration (BAC), $M P B A C$ is the difference between perceived and measured BAC, NO-ALC is a dummy for the NO-ALC experiment. Age is respondents' age (in years) and Female is a gender dummy. Significance level (**: $1 \%$; ${ }^{* *}: 5 \%$; ${ }^{*}$ : $10 \%$ ) based on robust standard errors (reported in parenthesis), clustered at the experimental session level (8 clusters).

effect should be controlled for in the analysis of risk aversion, in the same way in which it is important to control for the value of money.

Columns (3) and (4) of Table 3 show OLS estimates of Optimism regressed against the same set of controls as in the first two columns. While there is some evidence of a placebo effect (with subjects who overestimate their BAC expressing more pessimistic guesses), such evidence is not robust to the introduction of controls. Non-parametric analysis confirms the absence of any difference in optimism across treatments. ${ }^{15}$

\subsection{Alcohol and risk preferences}

We use the selling (ask) price of the lotteries elicited through the BDM procedure in Phase 1 to measure subjects' risk attitude. A risk neutral agent should evaluate any lottery exactly at its expected value while risk averse (loving) agents should instead ask lower (higher) prices. For each individual, we use as a summary measure of Risk aversion the average difference, across the ten lotteries, between the expected value and the selling price. On average, experimental subjects display a slight degree of risk aversion, with average expected value and selling price respectively equal to 22 and 20.66 euro. Subjects are on average willing to forgo 1.34 euro, that is $6 \%$ of expected gains, to avoid the risk associated

\footnotetext{
${ }^{15}$ A Mann Whitney test cannot reject the null hypothesis that Optimism is equal between ALC-T and ALCP (p-value 0.3615), between NO-ALC and ALC-P (p-value 0.5138), or between NO-ALC and ALC (p-values $0.1606)$.
} 
to lotteries. ${ }^{16}$ Thus, unlike what observed in several other lab experiments, our subjects display preferences that are on average very close to risk neutrality, in line with Rabin's calibration theorem (Rabin, 2000).

The selling price tends to be lower than the expected value particularly in the lotteries where the probability to win is higher, as displayed in Figure 4. The pattern around the expected value of the lotteries is consistent with the estimated shape of the probability weighting function (Gonzalez and $\mathrm{Wu}, 1999$ ).

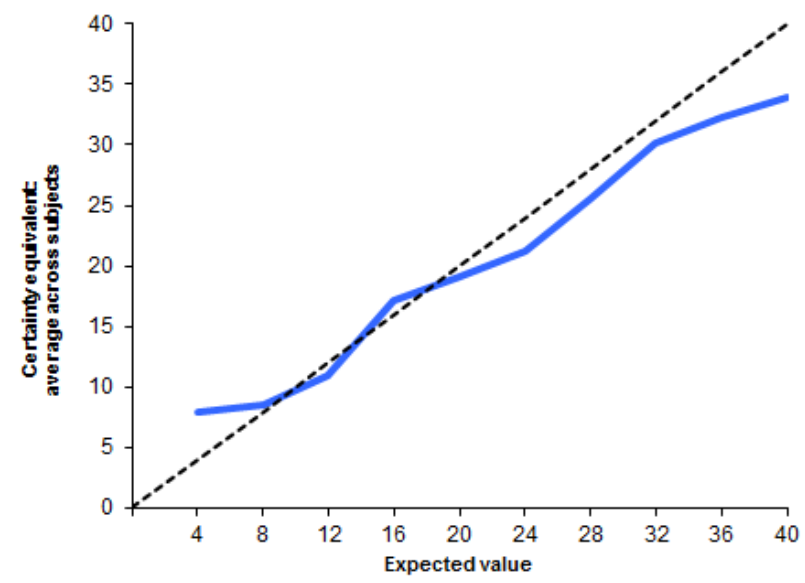

Figure 4: The average certainty equivalent (selling price) by lottery

Our key research question is whether risk attitude is affected by alcohol intoxication and changes across the experimental treatments. Columns (1) and (2) of Table 4 show OLS estimates of Risk aversion regressed against the same set of controls used in Table 3, namely the treatment variables $M B A C, M P B A C$ and $N O-A L C$, first without and then with the exogenous individual controls Age and Female. Common wisdom might suggest that alcohol increases risk seeking behavior. Our multivariate framework contradicts this conjecture, as no treatment variable turns out to be significantly related to risk aversion. Females appear to display a significantly higher degree of risk aversion than males. Column (3) adds individual controls for the marginal utility of money and for optimism: the coefficients of WTP and Optimism are not significantly different from zero and their inclusion does not alter the previous results.

Table 5 splits the average Risk aversion by gender and treatment, showing how the gender effect on risk attitudes is mediated by alcohol intoxication. In NO-ALC and ALC-P, involving no alcohol consumption, the choices of males and females are very similar on average and not very far from those associated with risk neutrality. By contrast, in ALC-T, under actual alcohol consumption, the behavior diverges sharply: while males exhibit slightly risk seeking preferences, females' risk aversion increases dramatically, as they are now willing to give up almost $30 \%$ of the expected gain to avoid uncertainty.

Splitting the sample along two dimensions (treatment and gender) implies a further re-

\footnotetext{
${ }^{16}$ As shown in Table 1, there are only minor differences between ALC and NO-ALC: the average Risk aversion is respectively 1.13 and 1.54 , that is $5.1 \%$ and $7 \%$ of expected gains.
} 
Table 4: Alcohol and risk preferences

\begin{tabular}{lccc}
\hline \hline \multirow{2}{*}{ Dependent variable } & Risk aversion & Risk aversion & \multicolumn{2}{c}{ Risk aversion } \\
\cline { 2 - 4 } & $(1)$ & $(2)$ & $(3)$ \\
\hline MBAC & -.2790 & -.2739 & $(2.2376)$ \\
MPBAC & $(1.6759)$ & $(1.9600)$ & -.7754 \\
& -2.7993 & -1.0813 & $(2.8707)$ \\
NO-ALC & $(3.1056)$ & $(2.9742)$ & -1.3713 \\
Age & -.3298 & -.4787 & $(1.4418)$ \\
& $(1.7146)$ & $(1.9179)$ & -.1324 \\
Female & & -.1467 & $(.0896)$ \\
WTP & & $(.1295)$ & $2.6021^{* *}$ \\
& & $3.1197^{* * *}$ & $(1.1566)$ \\
Optimism & & $(.8948)$ & .2427 \\
& & $(.1502)$ \\
Constant & & & .3010 \\
& & & $(.4116)$ \\
Observations & & -.5727 \\
R-Square & $1.8654^{*}$ & 3.8177 & $(3.5742)$ \\
\hline \hline
\end{tabular}

Notes: OLS regressions. The dependent variable, Risk aversion, is the average difference between the expected value and the ask price across the ten lotteries elicited in Phase 1 of the experiment. Regressors are defined in the notes to Table 3. Significance level (***:1\%; ${ }^{* *}: 5 \%$; $: 10 \%$ ) based on robust standard errors (reported in parenthesis), clustered at the experimental session level (8 clusters).

duction in the number of observations available to make inference. For this reason, most of the comparisons by treatment and gender turn out not to be significant, with the remarkable exception of the gender differences in risk aversion in the ALC-T condition $(p=.037) .{ }^{17}$ What emerges is therefore a gender specific compensation effect, with only intoxicated female subjects who compensate for the detrimental effects of alcohol by displaying a more prudent behavior. This finding is in line with Gustafson and Källmén (1990), who also detect a compensation effect for females in a cognitive task. Instead, similar risk attitudes emerge for subjects not exposed to alcohol consumption (NO-ALC and ALC-P). This is consistent with the recent findings of Filippin and Crosetto (2014), who argue that gender differences are usually not observed with elicitation methods characterized by changing probabilities and absence of a riskless alternative, like the BDM.

\subsection{Alcohol and time preferences}

Recall that One day, Seven days and Eight days are the additional sums required to postpone payment by the respective number of days (elicited in Phase 6 of the experiment).

\footnotetext{
${ }^{17}$ A similar argument applies when interacting gender with measured and misperceived BAC (MBAC and $M P B A C)$ in a multivariate framework. The level of measured alcohol intoxication is positively associated with risk aversion, with this effect being marginally significant for females and not significant for males. For the sake of space, this result is not reported, but it is available upon request.
} 
Table 5: Risk aversion by treatment and gender

\begin{tabular}{l|cc}
\hline \hline Treatment & Males & Females \\
\hline NO-ALC & .77 & 2.10 \\
ALC-P & .29 & 1.44 \\
ALC-T & -1.49 & 6.32 \\
\hline \hline
\end{tabular}

Figure 5 displays the distribution of these variables for subjects in ALC-T as compared to those who did not receive alcohol, showing that alcohol consumption makes individuals more impatient. In fact, the distribution of premia requested by subjects in the in ALC-T at seven and eight days stochastically dominates that of ALC-P and NO-ALC. This result is confirmed by non-parametric analysis. ${ }^{18}$
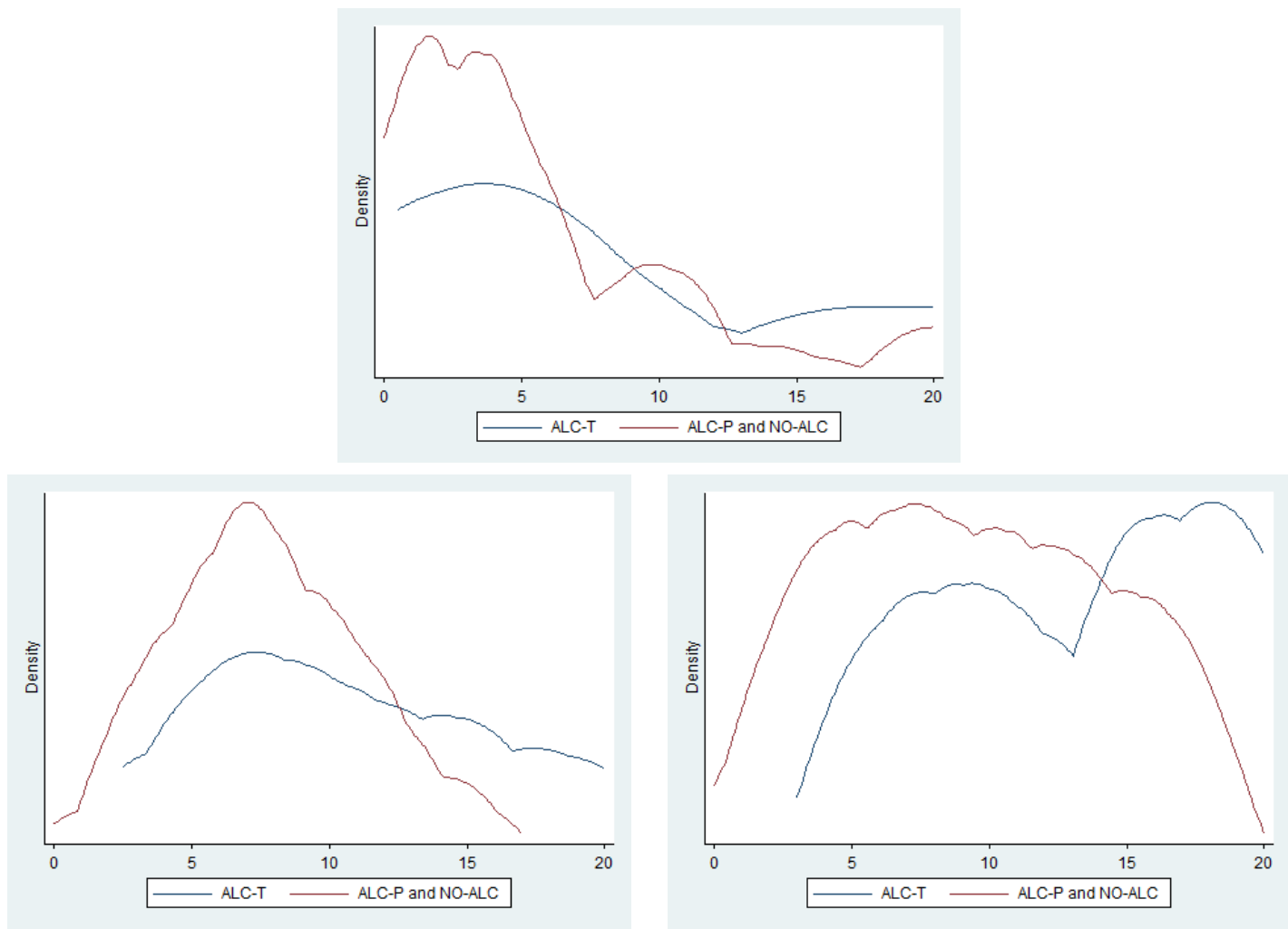

Figure 5: Distribution of One day (top panel), Seven days (bottom-left panel) and Eight days (bottom-right panel), which are the additional sums required to postpone payment by the respective number of days (elicited in Phase 6 of the experiment), by subjects in ALC-T and in the other treatments.

\footnotetext{
${ }^{18}$ At any future date, the average delay premium is higher in ALC-T than in ALC-P, with their difference being significant at seven and eight days. In particular, a battery of Mann Whitney tests marginally reject the null hypothesis that the average of Seven days is equal between ALC-T and ALC-P ( $\mathrm{p}$-value 0.0984), and the same is true for Eight days (p-value 0.0985). By contrast, the same tests cannot reject equality of these variables between NO-ALC and ALC-P (p-values 0.9323 and 0.8653 , respectively), nor can they reject equality of One day between ALC-T and ALC-P ( $\mathrm{p}$-value 0.1846).
} 
Our data can be used to calculate individual discount factors (relative to the present) at different points in time. Assuming that individual utility is linear in income and additively separable in time, the present discounted utility of a stream of income $\mathbf{y}=\left(y_{0}, \ldots, y_{T}\right)$, from time 0 to $T$, can be expressed as $U(\mathbf{y})=\sum_{t=0}^{T} \beta_{t} y_{t}{ }^{19}$ Standard neoclassical economics assumes exponential discounting: $\beta_{t}=\beta^{t}$, for some $\beta \in(0,1)$. This implies that the ratio between the discount factors of two adjacent moments in times is always constant: for any $t$, $\beta_{t+1} / \beta_{t}=\beta$. Rational individuals discounting the future exponentially should make timeconsistent choices. Behavioral economists have often explained the abundant evidence of time-inconsistent choices based on the idea that the discount factor is a hyperbolic or quasihyperbolic (rather than exponential) function of time. This means that $\beta_{t}$ drops faster from one period to the next when the present is involved ( $t$ close to zero) than in the future (when $t$ is higher). Our experiment allows testing exponential versus hyperbolic discounting. Since we have data for $t \in\{0,1,7,8\}$, and since $\beta_{0}=1$ by construction, so that $\beta_{1} / \beta_{0}=\beta_{1}$, we test the null hypothesis that $\beta_{1}=\beta_{8} / \beta_{7}$ against the alternative that $\beta_{1}<\beta_{8} / \beta_{7}$. On average, we find $\beta_{1}=.8108$ and $\beta_{8} / \beta_{7}=.9589$. The null hypothesis of their equality is rejected by a $t-$ test at the $1 \%$ significance level, both in the full sample and in the subsamples corresponding to each treatment, implying that our subjects discount the future in a hyperbolic-like rather than in an exponential way. ${ }^{20}$

To further investigate the effects of alcohol on time preferences, we construct a panel by using the individual discount factor at different points in time (relative to the present) as the longitudinal dimension. For each individual, we thus have four observations, which are calculated as follows: $\beta_{0}$ is set equal to one by construction, whereas for $t \in\{1,7,8\}$, $\beta_{t}=20 / y_{t}$, where $y_{t}$ is the total amount required to postpone payment at each future date, elicited in Phase 6 of the experiment. ${ }^{21}$ This panel structure allows running a random effect estimation of the longitudinal variable, called Patience, against the main regressors $(M B A C$, $M P B A C$ and NO-ALC, which are longitudinally constant for each individual), as well as a number of additional controls. Results are displayed in Table 6.

Column (1), which only considers the main determinants of interest, confirms that alcohol consumption raises impatience (it reduces Patience), both through a (highly significant) pharmacological effect and through a (less significant) placebo effect. Column (2) exploits the longitudinal dimension and introduces three time dummies for future dates, $1 D, 7 D$ and $8 D$, corresponding to one, seven and eight days from the date of the experiment. While this does not affect the results on the effects of alcohol, it confirms the previous result on the hyperbolic shape of time discounting. Contrary to the constant discount rate predicted by exponential discounting, postponing the payment by one day makes the discount factor drop faster when it takes place at present than in seven days. As shown by Column (3),

\footnotetext{
${ }^{19}$ The assumption of constant marginal instantaneous utility of money is common in the literature and it is a plausible approximation in light of the small degree of risk aversion we find in the data. Pre-multiplying discounted utility by a constant to rescale from monetary to utility units is irrelevant for choice and therefore omitted. To account for deviations from risk neutrality, we later include individual risk aversion among the controls in regression analysis.

${ }^{20}$ For an up to date discussion of the literature on hyperbolic discounting, and for an alternative interpretation in terms of subjective time compression, see Bradford et al. (2014).

${ }^{21}$ The experimental design is structured so that rational and risk-neutral agents ask for sums $y_{t}$ whose present discounted value is equal to the current payment, which is 20 euros, so $\beta_{t} y_{t}=20$.
} 
Table 6: Alcohol and time discounting, panel

\begin{tabular}{|c|c|c|c|c|c|c|}
\hline \multirow[t]{2}{*}{ Dependent variable } & Patience & Patience & Patience & Patience & Patience & Patience \\
\hline & $(1)$ & $(2)$ & (3) & $(4)$ & (5) & (6) \\
\hline$\overline{M B A C}$ & $\begin{array}{c}-.1084^{* * *} \\
(.0231)\end{array}$ & $\begin{array}{c}-.1084^{* * *} \\
(.0232)\end{array}$ & $\begin{array}{c}-.1066^{* * *} \\
(.0242)\end{array}$ & $\begin{array}{c}-.1034^{* * *} \\
(.0145)\end{array}$ & & \\
\hline$M P B A C$ & $\begin{array}{c}-.0842^{*} \\
(.0496)\end{array}$ & $\begin{array}{c}-.0842^{*} \\
(.0498)\end{array}$ & $\begin{array}{l}-.0807 \\
(.0528)\end{array}$ & $\begin{array}{l}-.0709 \\
(.0473)\end{array}$ & $\begin{array}{l}-.0615 \\
(.0452)\end{array}$ & \\
\hline$N O-A L C$ & $\begin{array}{l}-.0296 \\
(.0230)\end{array}$ & $\begin{array}{l}-.0296 \\
(.0232)\end{array}$ & $\begin{array}{l}-.0254 \\
(.0245)\end{array}$ & $\begin{array}{l}-.0235 \\
(.0272)\end{array}$ & $\begin{array}{l}-.0148 \\
(.0190)\end{array}$ & $\begin{array}{l}-.0138 \\
(.0150)\end{array}$ \\
\hline $1 D$ & & $\begin{array}{c}-.1892^{* * *} \\
(.0210)\end{array}$ & $\begin{array}{c}-.1892^{* * *} \\
(.0211)\end{array}$ & $\begin{array}{c}-.1892^{* * *} \\
(.0212)\end{array}$ & $\begin{array}{c}-.1759^{* * *} \\
(.0190)\end{array}$ & $\begin{array}{c}-.1698^{* * *} \\
(.0214)\end{array}$ \\
\hline $7 D$ & & $\begin{array}{c}-.2835^{* * *} \\
(.0190)\end{array}$ & $\begin{array}{c}-.2835^{* * *} \\
(.0191)\end{array}$ & $\begin{array}{c}-.2835^{* * *} \\
(.0192)\end{array}$ & $\begin{array}{c}-.2659^{* * *} \\
(.0198)\end{array}$ & $\begin{array}{c}-.2572 * * * \\
(.0224)\end{array}$ \\
\hline $8 D$ & & $\begin{array}{c}-.3150^{* * *} \\
(.0186)\end{array}$ & $\begin{array}{c}-.3150^{* * *} \\
(.0187)\end{array}$ & $\begin{array}{c}-.3150^{* * *} \\
(.0188)\end{array}$ & $\begin{array}{c}-.2935^{* * *} \\
(.0177)\end{array}$ & $\begin{array}{c}-.2816^{* * *} \\
(.0184)\end{array}$ \\
\hline Age & & & $\begin{array}{l}-.0025 \\
(.0030)\end{array}$ & $\begin{array}{l}-.0015 \\
(.0028)\end{array}$ & $\begin{array}{l}-.0015 \\
(.0028)\end{array}$ & $\begin{array}{r}-.0015 \\
(.0028)\end{array}$ \\
\hline Female & & & $\begin{array}{l}.0035 \\
(.0308)\end{array}$ & $\begin{array}{l}-.0155 \\
(.0264)\end{array}$ & $\begin{array}{l}-.0157 \\
(.0260)\end{array}$ & $\begin{array}{l}-.0152 \\
(.0251)\end{array}$ \\
\hline WTP & & & & $\begin{array}{c}-.00008 \\
(.0018)\end{array}$ & $\begin{array}{c}-.00006 \\
(.0018)\end{array}$ & $\begin{array}{c}-.00007 \\
(.0018)\end{array}$ \\
\hline Risk aversion & & & & $\begin{array}{c}.0055^{* * *} \\
(.0016)\end{array}$ & $\begin{array}{c}.0055^{* * *} \\
(.0016)\end{array}$ & $\begin{array}{c}.0055^{* * *} \\
(.0016)\end{array}$ \\
\hline Optimism & & & & $\begin{array}{l}.0025 \\
(.0028)\end{array}$ & $\begin{array}{l}.0026 \\
(.0028)\end{array}$ & $\begin{array}{l}.0027 \\
(.0027)\end{array}$ \\
\hline$M B A C^{*} 1 D$ & & & & & $\begin{array}{l}-.0834 \\
(.0552)\end{array}$ & $\begin{array}{l}-.0832 \\
(.0573)\end{array}$ \\
\hline$M B A C^{*} 7 D$ & & & & & $\begin{array}{c}-.1104^{* * *} \\
(.0364)\end{array}$ & $\begin{array}{c}-.1107^{* * *} \\
(.0384)\end{array}$ \\
\hline$M B A C^{*} 8 D$ & & & & & $\begin{array}{c}-.1350^{* * *} \\
(.0345)\end{array}$ & $\begin{array}{c}-.1359^{* * *} \\
(.0340)\end{array}$ \\
\hline$M P B A C^{*} 1 D$ & & & & & & $\begin{array}{r}-.0522 \\
(.0688)\end{array}$ \\
\hline$M P B A C^{*} 7 D$ & & & & & & $\begin{array}{l}-.0734 \\
(.0595)\end{array}$ \\
\hline$M P B A C^{*} 8 D$ & & & & & & $\begin{array}{l}-.1001 \\
(.0715)\end{array}$ \\
\hline Constant & $\begin{array}{c}.8448^{* * *} \\
(.0134)\end{array}$ & $\begin{array}{c}1.0418^{* * *} \\
(.0168)\end{array}$ & $\begin{array}{c}1.0978^{* * *} \\
(.0650)\end{array}$ & $\begin{array}{c}1.0440^{* * *} \\
(.0681)\end{array}$ & $\begin{array}{c}1.0216^{* * *} \\
(.0680)\end{array}$ & $\begin{array}{c}1.0133^{* * *} \\
(.0665)\end{array}$ \\
\hline Observations & 308 & 308 & 308 & 308 & 308 & 308 \\
\hline Overall R-Square & .022 & .5121 & .5154 & .5448 & .5495 & .5519 \\
\hline
\end{tabular}

Notes: Random effect panel estimate. The dependent variable, Patience, is the discount factor at different dates (set equal to one for the present and measured in one, seven and eight days by the ratio of the present payment -20 euros- to the total amount required to postpone payment at each future date, as elicited in Phase 6 of the experiment), constructed as a longitudinal variable with four observations for each individual. $1 D, 7 D$ and $8 D$ are dummies for the respective future dates. $M B A C^{*} 1 D, M B A C^{*} 7 D$ and $M B A C^{*} 8 D$, and $M P B A C^{*} 1 D, M P B A C^{*} 7 D$ and $M P B A C^{*} 8 D$, are interaction terms between these dummies and $M B A C$ and $M P B A C$, respectively. The other regressors are defined in the notes to Table 3 and Table 4 . Significance level $\left({ }^{* *}: 1 \%\right.$; ${ }^{* *}: 5 \%$; $\left.: 10 \%\right)$ based on robust standard errors (reported in parenthesis), clustered at the experimental session level (8 clusters). 
results are essentially unaffected by the introduction of additional (exogenous) individual controls, although the effect of MPBAC on Patience now turns insignificant. This suggests that only the pharmacological effect of alcohol on impatience is robust to controlling for sample composition, whereas the placebo effect is not.

Column (4) introduces our experimental measures of willingness to pay, risk aversion and optimism, finding that Patience is significantly and positively correlated with Risk aversion, but it is not significantly associated with the other two variables. The positive sign of the coefficient of risk aversion supports the standard psychological claim that risk loving subjects are also more impatient, a combination that may favor the involvement in risky behaviors. The strong correlation between impatience and attitude towards risk is also reassuring as far as the goodness of the risk aversion measure is concerned, supporting the absence of alcohol effects in increasing risk taking as a genuine result (see Section 4.3). ${ }^{22}$

Column (5) introduces three interaction terms between $M B A C$ and the time dummies $\left(M B A C^{*} 1 D, M B A C^{*} 7 D\right.$ and $\left.M B A C^{*} 8 D\right)$, in order to explore whether the pharmacological effect of alcohol on the time discount factor varies across different future dates. The results suggest that, relative to the present, subjects with high measured BAC do not discount a payment postponement by one day differently from other subjects, but they discount significantly more a postponement by one week or eight days.

In order to conduct a similar analysis about the differential effects of alcohol misperception, column (6) adds three interaction terms between MPBAC and the time dummies $\left(M P B A C^{*} 1 D, M P B A C^{*} 7 D\right.$ and $\left.M P B A C^{*} 8 D\right)$, but none of them turns out to be significant, suggesting that the overestimation of one's alcohol intoxication does not significantly raise impatience in future dates.

\subsection{Alcohol and altruistic preferences}

We now turn to results on social preferences and altruism, as elicited in phases 3 and 4 of the experiment. The descriptive statistics in Table 1 reveal two main observations. First, donations to Médecins Sans Frontières are substantially higher than those made in favor of LaVoce according to a battery of Mann Whitney tests ( $p<0.0001$ in all treatments), suggesting that subjects donate more to "hot" rather than "cold" projects. Second, it appears that overall donations made by subjects in NO-ALC are significantly higher than those observed in ALC (according to a Mann Whitney test, the p-value is 0.004 for donations to LaVoce and 0.007 for donations to Médecins Sans Frontières).

Table 7 reports random effect estimates from a panel model that uses for each individual the amounts donated to the two NGOs as longitudinal variable, called Altruism. Column (1) confirms that donations are significantly higher in NO-ALC. Within the ALC experiment, it shows a negative association of donations with both $M B A C$ and $M P B A C$, but the coefficients are not significantly different from zero. Column (2) adds $M S F$, a project dummy for Médecins Sans Frontières, and confirms that experimental subjects are significantly and substantially more willing to donate to this NGO than to LaVoce.info. Controlling for age and gender (column 3) confirms the previous results and, in addition, shows that donations are significantly higher for older subjects and for females, a result that is common

\footnotetext{
${ }^{22}$ Alcohol does not affect the interplay between risk tolerance and impatience, as shown by the fact that the coefficient of the interaction between risk aversion and the intoxication level is fairly close to zero. Results are not reported to save space but are available upon request.
} 
in the literature. While the difference in altruism between ALC and NO-ALC already becomes less significant when controlling for age and gender, it becomes non significant when also including subjects' willingness to pay (column 4) as an additional explanatory variable. Otherwise, the introduction of the latter variable makes no difference.

To better qualify the previous results, the last two columns of Table 7 respectively introduce the interaction terms between measured and misperceived BAC and the MSF dummy: $M B A C^{*} M S F$ and $M P B A C^{*} M S F$. Interestingly, while alcohol does not significantly alter donations to the "cold" receiver, it significantly reduces the amount given to the "hot" project. This reduction in altruism for the "hot" project is attributable to the pharmacological rather than the placebo effect of alcohol (column 6) and may signal a lower attachment to social norms.

Table 7: Alcohol and altruistic preferences

\begin{tabular}{|c|c|c|c|c|c|c|}
\hline Dependent variable & $\frac{\text { Altruism }}{(1)}$ & $\frac{\text { Altruism }}{(2)}$ & $\frac{\text { Altruism }}{(3)}$ & $\frac{\text { Altruism }}{(4)}$ & $\frac{\text { Altruism }}{(5)}$ & $\frac{\text { Altruism }}{(6)}$ \\
\hline$\overline{M B A C}$ & $\begin{array}{l}-1.8276 \\
(1.6432)\end{array}$ & $\begin{array}{l}-1.8276 \\
(1.6487)\end{array}$ & $\begin{array}{l}-2.0255 \\
(1.6699)\end{array}$ & $\begin{array}{l}-2.0060 \\
(1.6835)\end{array}$ & & \\
\hline$M P B A C$ & $\begin{array}{c}-.6253 \\
(1.5379)\end{array}$ & $\begin{array}{c}-.6253 \\
(1.5431)\end{array}$ & (1.6415) & (1.6519) & $\begin{array}{c}4537 \\
(1.6576)\end{array}$ & \\
\hline$N O-A L C$ & $\begin{array}{c}2.2787^{* *} \\
(1.0635)\end{array}$ & $\begin{array}{c}2.2787^{* *} \\
(1.0671)\end{array}$ & $\begin{array}{c}1.6529^{*} \\
(.9970)\end{array}$ & $\begin{array}{c}1.5002 \\
(1.0911)\end{array}$ & $\begin{array}{c}1.5002 \\
(1.0949)\end{array}$ & $\begin{array}{c}1.5002 \\
(1.0987)\end{array}$ \\
\hline MSF & & $\begin{array}{c}3.8909^{* * *} \\
(.6504)\end{array}$ & $\begin{array}{c}3.8909^{* * * *} \\
(.6548)\end{array}$ & $\begin{array}{c}3.8909^{* * * *} \\
(.6571)\end{array}$ & $\begin{array}{c}4.7510^{* * * *} \\
(.7664)\end{array}$ & $\begin{array}{c}5.0087^{* * *} \\
(.8901)\end{array}$ \\
\hline Age & & & $\begin{array}{l}.1669^{* *} \\
(.0799)\end{array}$ & $\begin{array}{l}.1645^{* *} \\
(.0803)\end{array}$ & $\begin{array}{l}.1645^{* *} \\
(.0805)\end{array}$ & $\begin{array}{l}.1645^{* *} \\
(.0808)\end{array}$ \\
\hline Female & & & $\begin{array}{l}2.3391^{*} \\
\text { (1.2129) }\end{array}$ & $\begin{array}{c}2.2824^{*} \\
(1.3036)\end{array}$ & $\begin{array}{c}2.2824^{*} \\
(1.3081)\end{array}$ & $\begin{array}{l}2.2824^{*} \\
(1.3126)\end{array}$ \\
\hline WTP & & & & $\begin{array}{l}.0483 \\
.1037)\end{array}$ & $\begin{array}{l}.0483 \\
(.1041)\end{array}$ & $\begin{array}{l}.0483 \\
(.1044)\end{array}$ \\
\hline$M B A C^{*} M S F$ & & & & & $\begin{array}{c}-4.7069^{* *} \\
(2.1597)\end{array}$ & $\begin{array}{c}-4.7284^{* *} \\
(2.1410)\end{array}$ \\
\hline$M B A C^{*} L V$ & & & & & $(1.69879)$ & $\begin{array}{c}.7163 \\
(1.7151)\end{array}$ \\
\hline$M P B A C^{*} M S F$ & & & & & & $\begin{array}{l}-.6126 \\
(2.1488)\end{array}$ \\
\hline$M P B A C^{*} L V$ & & & & & & $\begin{array}{c}1.5200 \\
(1.6125)\end{array}$ \\
\hline Constant & $\begin{array}{c}4.9621^{* * * *} \\
(.7666)\end{array}$ & $\begin{array}{c}3.0167^{* * *} \\
(.7482)\end{array}$ & $\begin{array}{l}-1.8183 \\
(1.5421)\end{array}$ & $\begin{array}{l}-1.9131 \\
(1.6502)\end{array}$ & $\begin{array}{l}-2.3431 \\
(1.7334)\end{array}$ & $\begin{array}{l}-2.4720 \\
(1.7926)\end{array}$ \\
\hline Observations & 154 & 154 & 154 & 154 & 154 & 154 \\
\hline Overall R-Square & .0827 & .2141 & .2765 & .2782 & .2968 & .2991 \\
\hline
\end{tabular}

Notes: Random effect panel estimate. The dependent variable, Altruism, is the donation to two NGOs (Médecins Sans Frontières and LaVoce, see Phases 3 and 4 of the experiment), constructed as a longitudinal variable with two observations for each individual. $M S F$ is a dummy for donations to Médecins Sans Frontières, and $M B A C^{*} M S F$ and $M P B A C^{*} M S F$ are its interactions with $M B A C$ and $M P B A C$. The other regressors are defined in the notes to Table 3. Significance level $\left.{ }^{* * *}: 1 \% ;{ }^{* *}: 5 \% ; *: 10 \%\right)$ based on robust standard errors (reported in parenthesis), clustered at the experimental session level (8 clusters).

\section{Conclusion}

In the last two decades, social scientists have devoted substantial effort to study the behavioral effects of alcohol consumption. In line with the anecdotal evidence, economic 
studies generally support the conclusion that alcohol abuse is positively associated with risk seeking and impatience. However, as most studies rely on field and survey data, identifying the causal relationship between alcohol and economic behavior remains an open question, as it is hard to exclude that results are driven by reverse causality and self-selection. In this study we provide causal evidence about the effects of alcohol intoxication (measured by the Blood Alcohol Concentration) on time, risk, and social preferences.

Our experimental design minimizes the impact of potential confounding factors. First, by randomly partitioning subjects into three different treatments -one with no reference to alcohol, a placebo and one in which subjects effectively consumed alcohol- we are able to disentangle the direct effects of alcohol consumption from those due to the expectation of having consumed alcohol (Malani and Houser, 2008). Second, in addition to eliciting risk, time and social preferences, our design allows us to build subjective measures of willingness to pay and the misperception of probabilities that are then used as further controls in the parametric analysis.

As far as risk aversion is concerned, our results confirm the findings of Burghart et al. (2013) that males' risk aversion is not affected by alcohol intoxication, even under a different elicitation method and in an experimental setting that is explicitly designed to control for self-selection. By contrast, we find some evidence that risk aversion of female subjects increases with alcohol intoxication.

Moving to time preferences, we detect a substantial and robust positive relationship between alcohol intoxication and impatience as measured by the amount that subjects require to postpone a certain payment to a future date. Additional observations qualify our experimental findings. First, our results reveal that the impact of alcohol intoxication on impatience is essentially pharmacological and goes beyond the expectation-mediated effects. Second, the relationship between alcohol consumption and impatience remains parametrically significant even after controlling for subjective measures of risk attitude, misperception of probabilities and willingness to pay. In this respect, we contribute to the flourishing literature studying the interplay between risk and time preferences as our estimates reveal the existence of a negative relationship between impatience and risk aversion.

We also investigate the effects of alcohol intoxication on subjects' generosity as measured by their attitude to donate money to two different NGOs, one involved in a "hot" humanitarian mission and one working on a "cold" project. Our data reveals two remarkable results. First, we find that subjects donate significantly more to the "hot" NGO. Second, we observe a significant pharmacological effect of alcohol consumption in decreasing donations to the "hot" NGO, possibly signaling a lower conformity to social norms.

By estimating the causal effects of alcohol intoxication on risk, time and social preferences, our results also contribute to a growing field of studies in behavioral economics, which, building on evidence from both psychology and neuro-sciences, describes the decision process as a compromise between deliberation and emotions. According to dual-self models, the relative weight in decision-making of the deliberative and of the emotional self is affected by an individual's cognitive load, which reduces the ability to exert willpower and thus shifts weight towards the impulsive and emotional self. ${ }^{23}$ If one accepts that alco-

\footnotetext{
${ }^{23}$ See for instance Bernheim and Rangel (2004); Levine and Fudenberg (2006). Loewenstein and O'Donoghue (2007) argue that while the affective system has initial control, the deliberative system can influence behavior
} 
hol reduces the ability to exert willpower and self-control, its effects can be interpreted as analogous to those of cognitive load: alcohol intoxication makes decisions more determined by emotions and less by deliberation. According to this view, by exploiting an exogenous variation in blood alcohol concentration, our experiment may be interpreted as shedding light on the behavioral implications of the emotional self and providing prima facie evidence that the emotional self is indeed impulsive, leading individuals to make decisions, which they may subsequently regret, excessively driven by immediate impulses and too little (relative to a sober condition) by the calculation of future consequences for oneself and for other people. $^{24}$

\footnotetext{
through the exertion of willpower.

${ }^{24}$ Partially in line with our results, a recent experimental study by Benjamin et al. (2013) shows that cognitive load increases both small-stakes risk aversion and short-run discounting.
} 


\section{References}

Abrams, D., Hopthrow, T., Hulbert, L., Frings, D., 2006. Groupdrink? The effect of alcohol on risk attraction among groups versus individuals. Journal of Studies on Alcohol 67 (4), 628-636.

Ainslie, G., Haendel, V., 1983. Expectations mediate objective physiological placebo effects. In: Houser, D., McCabe, K. (Eds.), Etiologic Aspects of Alcohol and Drug Abuse. Vol. 12. pp. 311-327.

Anderhub, V., Güth, W., Gneezy, U., Sonsino, D., 2001. On the interaction of risk and time preferences: An experimental study. German Economic Review 2 (3), 239 - 253.

Anderson, L. R., Mellor, J. M., 2008. Predicting health behaviors with an experimental measure of risk preference. Journal of Health Economics 27 (5), 1260-1274.

Andreoni, J., Sprenger, C., 2012. Risk preferences are not time preferences. American Economic Review 102 (7), 3357-76.

Barsky, R. B., Juster, F. T., Kimball, M. S., Shapiro, M. D., 1997. Preference parameters and behavioral heterogeneity: An experimental approach in the health and retirement study. The Quarterly Journal of Economics 112 (2), 537-579.

Becker, G., DeGroot, M., Marschak, J., 1964. Measuring utility by a single-response sequential method. Behavioral Science 9, 226-236.

Benjamin, D. J., Brown, S. A., Shapiro, J. M., 2013. Who is 'behavioral'? cognitive ability and anomalous preferences. Journal of the European Economic Association 11 (6), 1231-1255.

Bernheim, B. D., Rangel, A., 2004. Addiction and cue-triggered decision processes. American Economic Review 94 (5), 1558-1590.

Bickel, W., Odum, A., Madden, G., 2001. Delay discounting of money and alcohol in actively using alcoholics, currently abstinent alcoholics, and controls. Psychopharmacology (Berl) 154 (3), 243-250.

Bradford, W. D., Dolan, P., Galizzi, M. M., 2014. Looking Ahead: Subjective Time Perception and Individual Time Discounting. CEP Discussion Papers 1255, Centre for Economic Performance, LSE.

Breslin, F. C., Sobell, M. B., Cappell, H., Vakili, S., Poulos, C. X., 1999. The effects of alcohol, gender, and sensation seeking on the gambling choices of social drinkers. Psychology of Addictive Behaviors 13 (3), 243-252.

Buonanno, P., Vanin, P., 2013. Bowling alone, drinking together. Empirical Economics 44 (3), $1635-1672$.

Burghart, D., Glimcher, P., Lazzaro, S., 2013. An expected utility maximizer walks into a bar... Journal of Risk and Uncertainty 46 (3), 215-246. 
Chatterji, P., DeSimone, J., 2005. Adolescent drinking and high school dropout. NBER Working Papers 11337, National Bureau of Economic Research, Inc.

Chatterji, P., DeSimone, J., 2006. High school alcohol use and young adult labor market outcomes. NBER Working Papers 12529, National Bureau of Economic Research, Inc.

Crosetto, P., Filippin, A., Feb. 2013. A theoretical and experimental appraisal of five risk elicitation methods. Jena Economic Research Papers 2013-009, Friedrich-Schiller-University Jena, Max-Planck-Institute of Economics.

Cutter, H. S., Green, L. R., Harford, T. C., 1973. Levels of risk taken by extraverted and introverted alcoholics as a function of drinking whisky. British Journal of Social \& Clinical Psychology 12 (1), 83-89.

Dee, T. S., 1999. State alcohol policies, teen drinking and traffic fatalities. Journal of Public Economics 72 (2), 289-315.

DeSimone, J., 2007. Fraternity membership and binge drinking. Journal of Health Economics 26 (5), 950-967.

DeSimone, J., 2009. Fraternity membership and drinking behavior. Economic Enquiry 47 (2), 337-350.

Dills, A. K., Miron, J., 2003. Alcohol prohibition and cirrhosis. American Law and Economics Review 6 (2), 285-318.

Drichoutis, A., Nayga, R., 2010. Eliciting risk and time preferences under induced mood states. MPRA Paper 25731, University Library of Munich, Germany.

Duarte, R., Escario, J. J., 2006. Alcohol consumption and truancy among Spanish adolescents: a count-data approach. Economics of Education Review 25 (2), 179-187.

Field, M., Christiansen, P., Cole, J., Goudie, A., 2007. Delay discounting and the alcohol stroop in heavy drinking adolescents. Addiction 102 (4), 579-586.

Filippin, A., Crosetto, P., 2014. A Reconsideration of Gender Differences in Risk Attitudes.

Fischbacher, U., 2007. z-tree: Zurich toolbox for ready-made economic experiments. Experimental Economics 10, 171-178.

Galizzi, M. M., Miraldo, M., 2012. Are you what you eat? Experimental evidence on risk preferences and health habits. Working Papers 9792, Imperial College, London, Imperial College Business School.

Gonzalez, R., Wu, G., 1999. On the shape of the probability weighting function. Cognitive Psychology 38 (1), 129-166.

Green, L., Myerson, J., 2004. A discounting framework for choice with delayed and probabilistic rewards. Psychological Bulletin 130 (5), 769-792. 
Grossman, M., Kaestner, R., Markowitz, S., 2005. An investigation of the effects of alcohol consumption and alcohol policies on youth risky sexual behaviors. American Economic Review 95 (2), 263-266.

Grossman, M., Markowitz, S., 2005. I did what last night? Adolescent risky sexual behaviors and substance abuse. Eastern Economic Journal 31 (1), 383-405.

Gustafson, R., Källmén, H., 1990. Alcohol and the compensation hypothesis: a test with cognitive and psychomotor tasks. Perceptual and Motor Skills 71, 1367-1374.

Harrison, G. W., Rutström, E. E., 2008. Risk Aversion in the Laboratory. In: Cox, J. C., Harrison, G. W. (Eds.), Risk Aversion in Experiments. Vol. 12 of Research in Experimental Economics. Emerald Group Publishing Limited, pp. 41-196.

Holt, C., Laury, S., 2002. Risk aversion and incentive effects. American economic review $92(5), 1644-1655$.

Holt, D. D., Green, L., Myerson, J., 2003. Is discounting impulsive? Evidence from temporal and probability discounting in gambling and non-gambling college students. Behavioural Processes 64 (3), $355-367$.

Kirby, K., Petry, N., 2004. Heroin and cocaine abusers have higher discount rates for delayed rewards than alcoholics or non-drug-using controls. Addiction 99 (4), 461-471.

Koch, S. F., McGeary, K. A., 2005. The effect of youth alcohol initiation on high school completion. Economic Inquiry 43 (4), 750-765.

Kremer, M., Levy, D., 2008. Peer effects and alcohol use among college students. Journal of Economic Perspectives 22 (3), 189-206.

Lane, S., Cherek, D., Pietras, C., Tcheremissine, O., 2004. Alcohol effects on human risk taking. Psychopharmacology $172(1), 68-77$.

Levine, D. K., Fudenberg, D., 2006. A dual-self model of impulse control. American Economic Review 96 (5), 1449-1476.

Levitt, S. D., Porter, J., 2001. How dangerous are drinking drivers? Journal of Political Economy 109 (6), 1198-1237.

Loewenstein, G., O'Donoghue, T., 2007. The heat of the moment: Modeling interactions between affect and deliberation. mimeo.

Lundborg, P., 2006. Having the wrong friends? Peer effects in adolescent substance use. Journal of Health Economics 25 (2), 214-233.

Malani, A., Houser, D., 2008. Expectations mediate objective physiological placebo effects. In: Houser, D., McCabe, K. (Eds.), Neuroeconomics (Advances in Health Economics and Health Services Research, Volume 20). Vol. 12. Emerald Group Publishing Limited, pp. 311-327. 
Markowitz, S., 2005. Alcohol, drugs and violent crime. International Review of Law and Economics 25 (1), 20-44.

Meier, S. E., Brigham, T. A., Ward, D. A., Myers, F., Warren, L., 1996. Effects of blood alcohol concentrations on negative punishment: Implications for decision making. Journal of Studies on Alcohol 57 (1), 85-96.

Menon, M., Perali, F., 2009. Eliciting risk and time preferences in field experiments: Are they related to cognitive and non-cognitive outcomes? Are circumstances important? Rivista Internazionale di Scienze Sociali 117 (3), 593-630.

Moore, S. C., Cusens, B., 2010. Delay discounting predicts increase in blood alcohol level in social drinkers. Psychiatry Research 179 (3), 324 - 327.

Ortner, C. N. M., MacDonald, T. K., Olmstead, M. C., 2003. Alcohol intoxication reduces impulsivity in the delay-discounting paradigm. Alcohol and Alcoholism 38 (2), 151-156.

Petry, N. M., 2001. Delay discounting of money and alcohol in actively using alcoholics, currently abstinent alcoholics, and controls. Psychopharmacology (Berl) 154 (3), 243-250.

Poulos, C., Le, A., Parker, J., 1995. Impulsivity predicts individual susceptibility to high levels of alcohol self administration. Behavioral Pharmacology 6 (8), 810-814.

Proestakis, A., Cortés Aguilar, A., Espín Martín, A., Exadaktylos, F., Segun, O., Palacios García, L. A., 2013. The separate effects of self-estimated and actual alcohol intoxication on risk-taking: A field experiment. Journal of Neuroscience, Psychology, and Economics $6(2), 115-135$.

Rabin, M., 2000. Risk aversion and expected-utility theory: A calibration theorem. Econometrica 68 (5), 1281-1292.

Reynolds, B., Richards, J. B., de Wit, H., 2006. Acute-alcohol effects on the experiential discounting task (EDT) and a question-based measure of delay discounting. Pharmacology Biochemistry and Behavior 83 (2), $194-202$.

Richards, J. B., Zhang, L., Mitchell, S., de Wit, H., 1999. Delay or probability discounting in a model of impulsive behavior: effect of alcohol. Journal of the Experimental Analalysis of Behavior 71 (2), $121-143$.

Sjöberg, L., 1969. Alcohol and gambling. Psychopharmacologia 14 (4), 284-98.

Vuchinich, R. E., Simpson, C. A., 1998. Hyperbolic temporal discounting in social drinkers and problem drinkers. Experimental and Clinical Psychopharmacology 6 (3), 292-305. 


\section{Appendix A. Experimental Instructions}

The experimental instructions were originally written in Italian to enable us to run the experiments at the University of Milan. In what follows, we report the literal translation in English.

\section{Appendix A.1. Welcome}

Thanks for participating to this experiment on decision making. By following these instructions, you can win an amount (included between 0 and 40 euro) that will be paid once the experiment is concluded. Your choices as well as any personal information will remain be anonymously analyzed in aggregate terms and used for scientific purposes only. Finally, there are not correct or wrong answers to the following tasks. Your choices will exclusively depend upon personal characteristics such as your preferences and your attitude to participate to gambles. It is extremely important that you make your choices having completely understood these instructions. For this reason, feel free to ask questions about the instructions.

\section{Appendix A.2. The experiment}

In this experiment you will participate to 7 consecutive phases, in each of which you will be required to make some economic choices. At the beginning of each phase, you will be given the instructions for the corresponding decisional task. Although you will participate to 7 consecutive phases, your final earnings uniquely depend on the outcome of one single phase. In particular, the phase used to determine your final earnings will be randomly selected at the end of the experiment by drawing one of seven cards, numbered from 1 to 7 . Since phases have the same probability of being selected, you should make each choice as if it was the one effectively used to determine your final earnings. If you do not have any question, we can start with the experiment.

\section{The Market Mechanism BDM}

During the experiment, you will be required to make some choices using a peculiar market mechanism called BDM (from the names of the 3 economists that invented it, Becker, De Groot and Marschak).

In this market mechanism you will interact either with a seller robot or a buyer robot.

Seller robot. Suppose that you want to buy a generic item $X$ from a seller robot and you are endowed with 10.00 euro. The bargaining is conducted as follows. The seller robot selects the price of $X$ randomly, by picking a value included between 0.00 and 10.00 euro (in steps of 0.10 euro) with equal probability. Before knowing the price selected by the seller robot, you will be asked to state the maximum price (included between 0.00 and 10.00 euro, in steps of 0.10 euro) you are willing to pay for $X$. If the price stated by you is lower than the price selected by the seller robot, then no agreement is reached: you do not buy X and the seller robot does not receive any amount of money. On the contrary, if the price stated by you is higher than or equal to the price selected by the seller robot, then an agreement is reached: you buy $X$ paying to the seller robot what it haw randomly selected. Example. Suppose the price you are willing to pay for $X$ is 6euro and the price selected by the seller robot is 4.90 euro. Given the previous instructions, an agreement is reached. You buy X paying 4.90 euro 
to the seller robot. It is easy to show that there is no incentive to miss-report the amount you are willing to pay for $X$. Suppose that, although you are willing to pay 6.00 euro for $X$, you state a lower price, say 4.00 euro. Suppose that the seller robot selects a price equal to 4.10 euro. Although you would have been happy to buy $X$ for 4.10 euro, the agreement is not reached since the price stated by you is lower than the price selected by the seller robot. Generally speaking, you should never report a lower price than what you are willing to pay for $X$ because your choice does not affect the selling price and you might lose the opportunity to buy the item for a favorable exchange. Instead, suppose that, although you are willing to pay 6.00 euro for $X$, you state a higher price, say 7euro. Suppose that the seller robot selects a price equal to 6.50 euro. In this case an agreement is reached but you have to pay a price which is higher than what you are willing to pay. Generally speaking, you should never report a higher price than what you are willing to pay for $\mathrm{X}$ because your choice does not affect the selling price and you might buy the item for an unfavorable too high price

Buyer robot. What said above also holds in a slightly different context in which you interact with a buyer robot. Suppose you have the opportunity to sell a generic item $Y$ to a buyer robot which is endowed with 10.00 euro. The bargaining is conducted as follows. The buyer robot selects the price it is willing to pay for $\mathrm{Y}$ randomly, by picking a value included between 0.00 and 10.00 euro (in steps of 0.10 euro) with equal probability. Before knowing the price selected by the buyer robot, you will be asked to state the minimum price (between 0.00 and 10.00 euro, in steps of 0.10 euro) you require to sell $\mathrm{Y}$. If the price stated by you is higher than the price selected by the buyer robot, then no agreement is reached: you do not sell $\mathrm{Y}$ and the buyer robot does not pay any amount of money to you. On the contrary, if the price stated by you is lower than or equal to the price selected by the buyer robot, than an agreement is reached: you sell $Y$ to the buyer robot for price it has selected. Even in this case, there is no incentive to misreport the amount you require to sell $\mathrm{Y}$.

Phase 1

Please look at the following table carefully

\begin{tabular}{|c|c|c|c|}
\hline \multirow{2}{*}{ LOTTERY } & \multicolumn{2}{|c|}{ OUTCOME } & \multirow{2}{*}{ PRICE } \\
\hline & You receive 40 euro if the number is & You receive nothing if the number is & \\
\hline L1 & $1,2,3,4$ & $5,6,7,8,9,10$ & \\
\hline $\mathrm{L} 2$ & $1,2,3,4,5,6,7,8,9$ & 10 & \\
\hline L3 & $1,2,3,4,5$ & $6,7,8,9,10$ & \\
\hline L4 & 1 & $2,3,4,5,6,7,8,9,10$ & \\
\hline L5 & $1,2,3,4,5,6$ & $7,8,9,10$ & \\
\hline L6 & $1,2,3$ & $4,5,6,7,8,9,10$ & \\
\hline L7 & $1,2,3,4,5,6,7,8,9,10$ & & \\
\hline L8 & $1,2,3,4,5,6,7,8$ & 9,10 & \\
\hline L9 & 1,2 & $3,4,5,6,7,8,9,10$ & \\
\hline L10 & $1,2,3,4,5,6,7$ & $8,9,10$ & \\
\hline
\end{tabular}


The previous table reports 10 lotteries, numbered from L1 to L10. As you see from the table, the only difference between lotteries concerns the probability of receiving a prize of 40 euro. For each line of the table, you are asked to state in the last column (PRICE) the minimum price you are willing to sell the right to participate to the corresponding lottery to a buyer robot. At the end of the experiment, if this phase is selected, your final earnings will be determined according to the following procedure.

Which lottery? Although you are asked to make a choice for each of the 10 lotteries reported in the table, you final earnings will uniquely depend on the outcome of a single lottery. In particular, the lottery to use will be randomly selected by drawing one of ten cards, numbered from L1 to L10, such that the probability of each lottery is the same.

Do you participate to the lottery or sell this opportunity? Whether you will (or won't) participate to the selected lottery depends on the outcome of the BDM market mechanism explained above. In particular, the price that a buyer robot is willing to pay for participating to the selected lottery will be randomly selected by picking a value included between 0.00 and 40.00 euro (in 0.10 euro steps). If the price selected by the buyer robot is higher than or equal to the price stated by you for the selected lottery, then an agreement is reached and you sell the right to participate to the lottery for the price of the buyer robot. On the contrary, if the price selected by the buyer robot is lower than the price stated by you for the selected lottery, then an agreement is not reached: you will not receive any price from the buyer robot and you will participate to the selected lottery.

The outcome of the selected lottery. On the contrary, if the price selected by the buyer robot is lower than the price stated by you for the selected lottery, then an agreement is not reached: you will not receive any price from the buyer robot and you will participate to the selected lottery. In this case, we will randomly draw one of ten balls, numbered from 1 to 10, with equal probability and your earnings will be determined according to the rules of the selected lottery reported in the table.

\section{Phase 2}

Look at this item carefully. It is a combo radio-videogame that includes batteries.

You are asked to state the maximum price you are willing to pay (between 0.00 euro to 20.00 euro, in steps of 0.10 euro) for buying this item from a seller robot knowing that in this phase you are endowed with 20.00 euro.

At the end of the experiment, if this phase will be randomly selected, your final earnings will be determined according to the BDM market mechanism explained above. In particular, the seller robot will randomly select the price it requires to sell the item by picking a value included between 0.00 and 20.00 euro (in 0.10 euro steps). If the price stated by you is higher than the price selected by the seller robot, than an agreement is reached: you buy the item for the price selected by the seller robot and you receive an amount given by the difference between 20.00 euro and the price you paid. On the contrary, if the price stated by you is lower than that selected by the seller robot, no agreement is reached: you do not buy the item and receive an amount of 20.00 euro.

MAXIMUM PRICE YOU ARE WILLING TO PAY FOR THE ITEM (between 0.00 and 20.00 euro): 


\section{Phase 3}

In this phase, you are asked to state the amount (between 0.00 euro to 20.00 euro, in steps of 0.10 euro) you want to donate to "LaVoce.info" knowing that in this phase you are endowed with 20.00 euro.

At the end of the experiment, if this phase is selected, your final earnings will depend on the amount you have donated to "LaVoce.info." In particular, you will receive an amount that is equal to the difference between 20.00 euro and what you have donated to "LaVoce.info." LaVoce.info is a free online press that is mainly managed by economists working for universities and other institutions. Its articles focus on economic, political and social issues and its editorial style is in the middle between non-specialized press and academic language. LaVoce.info self-financed by its members and authors of the articles work on voluntary base. Within 14 days from the end of the experimental sessions, your donation together with those of the participants overall sessions will be sent to "LaVoce.info" through postal transfer. The details of the postal transfer and the list of anonymous donations made by the participants to this experiment will be emailed on request.

AMOUNT TO DONATE TO “LAVOCE.INFO” (between 0.00 and 20.00 euro):

\section{Phase 4}

In this phase, you are asked to state the amount (between 0.00 euro to 20.00 euro, in steps of 0.10 euro) you want to donate to "Medecins Sans Frontieres" knowing that in this phase you are endowed with 20.00 euro.

At the end of the experiment, if this phase is selected, your final earnings will depend on the amount you have donated to "Medecins Sans Frontieres" In particular, you will receive an amount that is equal to the difference between 20.00 euro and what you have donated to "Medici sans Frontier."

"Medecins Sans Frontieres" is a humanitarian institution that offers medical and sanitary support in war areas.

Within 14 days from the end of the experimental sessions, your donation together with those of the participants overall sessions will be sent to "Medecins Sans Frontieres" through postal transfer. The details of the postal transfer and the list of anonymous donations made by the participants to this experiment will be emailed on request.

AMOUNT TO DONATE TO “MEDECINS SANS FRONTIERES” (between 0.00 and 20.00 euro):

\section{Phase 5}

In this phase, each participant will be assigned a maze of 52 standard poker cards. Given his/her maze, for each participant, an experimenter will randomly select a subset of 21 unobserved cards. For simplicity, let us refer to this subset of cards with the word the "sample." Please chose one card of your sample and observe it. At the end of the experiment, if this phase is selected, you will paid 1.00 euro for each card in your sample reporting the same color (black or red) of that you have just selected. 
Moreover, you are asked to guess the number of cards in your sample reporting the same color (black or red) of that you have just selected. If your conjecture is correct, you will receive an additional amount of 10.00 euro.

NUMBER OF CARDS IN YOUR SAMPLE REPORTING THE SAME COLOR OF THE ONE YOU HAVE SELECTED (BETWEEN 0 AND 21, INCLUDING THE ONE YOU HAVE SELECTED):

\section{Phase 6}

In this phase you are endowed with 20 euro.

As follows, we ask you to state the minimum additional amount (between 0.00 and 20 euro) you would require from a hypothetical borrower to post-pone the payment by 1, 7 and 8 days respectively. In all these cases, the payment will occur through debit card.

At the end of the experiment, if this phase is selected, one of the three possible dates will be randomly chosen by drawing one of three cards, numbered 1, 7 and 8 respectively. Given the date and following the BDM market mechanism explained above, the borrower robot will select the additional amount it is willing to pay to postpone the payment at that date by randomly picking a value included between 0.00 and 20.00 euro (in 0.10 euro steps) with equal probability. If the amount selected by the borrower robot is higher than the amount stated by you, then an amount of 20.00 euro plus what selected by the borrower robot will be transferred to your debit card at the corresponding date. On the contrary, if the amount selected by the borrower robot is lower than the amount stated by you, then at the end of the experiment you will be paid 20 euro in cash.

MINIMUM ADDITIONAL AMOUNT (BETWEEN 0.00 AND 20.00 euro) YOU REQUIRE FROM THE BORROWER ROBOT TO POSTPONE THE PAYMENT OF 20.00 euro BY 1 DAY:

MINIMUM ADDITIONAL AMOUNT (BETWEEN 0.00 AND 20.00 euro) YOU REQUIRE FROM THE BORROWER ROBOT TO POSTPONE THE PAYMENT OF 20.00 euro BY 7 DAYS:

MINIMUM ADDITIONAL AMOUNT (BETWEEN 0.00 AND 20.00 euro) YOU REQUIRE FROM THE BORROWER ROBOT TO POSTPONE THE PAYMENT OF 20.00 euro BY 8 DAYS: 


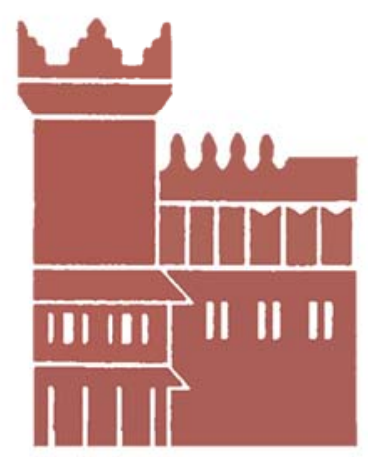

Alma Mater Studiorum - Università di Bologna DEPARTMENT OF ECONOMICS

Strada Maggiore 45

40125 Bologna - Italy

Tel. +39051 2092604

Fax +390512092664

http://www.dse.unibo.it 